\title{
Over-time Fluctuations in Parenting and Adolescent Adaptation Within Families: A Systematic Review
}

\author{
Savannah Boele ${ }^{1}$ D $\cdot$ Jaap Denissen ${ }^{1} \cdot$ Neha Moopen $^{2} \cdot$ Loes Keijsers $^{1}$
}

Received: 25 May 2019/ Accepted: 31 July 2019/ Published online: 8 August 2019

(c) The Author(s) 2019

\begin{abstract}
Parenting theories describe that fluctuations in parenting and adolescent adaptation are linked within the same families. Studies on these so-called 'within-family' effects between parenting and adolescent adaptation are summarized in the current systematic review. Through a database and backward citation search, 46 eligible peer-reviewed studies were found, which were published between 2002 and 2018. The studies assessed a variety of parenting (i.e., support, control, negative interaction, time spent together, relationship quality, and differential parenting) and adaptation dimensions (i.e., externalizing and internalizing problems, affect, and interpersonal, academic, and physical functioning). Concerning the design of the studies, typical measurement intervals were either days $(k=10)$ or 6 months or longer $(k=30)$. Moreover, only six studies tested (and mostly found) heterogeneity in random slopes, and 20 studies used a moderation approach to explain heterogeneity. Of the concurrent associations, some (but not all) of the few available studies suggested that increases in parental control and support and decreases in negative interaction within a family were associated with decreases in externalizing and internalizing problems, as well as other indices of adolescent maladaptation. However, with respect to time-lagged associations, there is to date hardly any empirical evidence that parenting and adolescent adaptation predict each other within families. Based on the identified theoretical lacunas and empirical limitations, directions are provided for future within-family parenting studies.
\end{abstract}

Keywords Systematic review $\cdot$ Parenting $\cdot$ Parent-child relationship $\cdot$ Adolescence $\cdot$ Within-family $\cdot$ Within-person

\section{Introduction}

A vast amount of research has shown that families differ from each other. In families with more parental monitoring and support, for instance, adolescents are generally better adapted than in other families. Indeed, meta-analyses highlight that adequate parenting is linked to important adolescent outcomes, such as internalizing and externalizing problems (Hoeve et al. 2009; Pinquart 2017a, 2017b). However, parenting not only has trait-like characteristics, but it is also

Electronic supplementary material The online version of this article (https://doi.org/10.1007/s40894-019-00127-9) contains supplementary material, which is available to authorized users.

Savannah Boele

s.boele@uvt.nl

1 Department of Developmental Psychology, Tilburg University, Prof. Cobbenhagenlaan 225, PO Box 90153, 5000 LE Tilburg, The Netherlands

2 School of Social and Behavioral Sciences, Tilburg University, Tilburg, The Netherlands a dynamic process in which adolescents and parents mutually influence each other (Bell 1968; Granic and Patterson 2006; Pardini 2008). Conceptually, these dynamic parenting processes can manifest themselves as associations between over-time fluctuations in parenting and adolescent adaptation within the same family. For example, adolescents might express less problem behavior after their own parents set up stricter rules, as illustrated in Fig. 1. Recently, it has been suggested that existing parenting studies that tap into relative differences between families might not optimally be suited to (also) detect or draw conclusions regarding how changes in parenting affect adolescent adaptation (Berry and Willoughby 2017; Hamaker 2012; Keijsers 2016). Therefore, alternative methods have been proposed for analyzing longitudinal data that better capture these dynamic parenting processes (e.g., Hamaker et al. 2015). The current review summarizes and discusses empirical studies estimating both concurrent and time-lagged within-family associations between parenting and adolescent adaptation. By synthesizing this body of literature, the aim is to obtain an overview of the available studies and to synthesize their findings. 


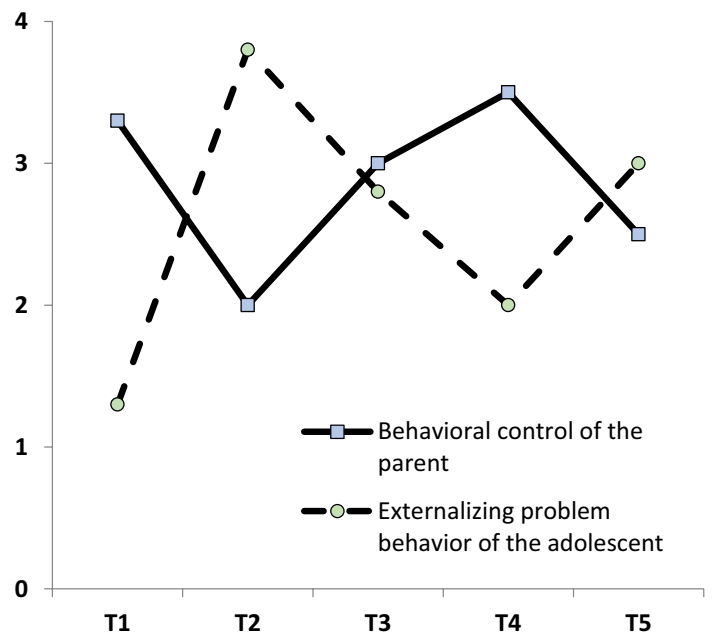

Fig. 1 Hypothetical longitudinal data of one individual family assessed five consecutive times, illustrating a negative within-family link between control and externalizing problems (at times when control was high, externalizing problems were lower)

Furthermore, recommendations for future directions are provided based on identified limitations and caveats of the studies that have been published so far.

\section{Theories Describing Parenting Processes}

In the seminal integrative macro model of Darling and Steinberg (1993), parenting practices (domain-specific parental behaviors, such as punishment) are conceptualized as the mechanisms through which parents can directly influence their adolescent's adaptation. Because parents fluctuate in their practices over time and situations, parenting practices might explain fluctuations and development in adolescent's adaptation, in contrast to parenting styles (Baumrind 1971) that are defined by them as a stable contextual characteristic between the parent and the child (Darling and Steinberg 1993). Therefore, Darling and Steinberg recommended to study parenting practices to understand the processes through which parents influence their adolescent's adaptation. Hence, although not explicitly mentioned, they proposed that parenting should be studied at the within-family level, i.e., the level on which fluctuations in parenting can be observed.

Parenting, however, spans different domains and behaviors. For example, in the monitoring literature, it has been theorized that exerting more behavioral control decreases adolescents' externalizing problem behavior (Patterson and Stouthamer-Loeber 1984, but see Kerr and Stattin 2000). According to the self-determination theory (Ryan and Deci 2000), however, an increase in parental psychological control could be followed by a decline in adolescent adaptation via the frustration of the need for autonomy and competence, whereas an increase in parental autonomy support could be followed by an increase in adolescent adaptation because this satisfies the need for autonomy (Soenens et al. 2007). Thus, such parenting theories describe over-time processes through which adolescents' adaptation fluctuate (i.e., showing less aggressive behavior) in concert with fluctuations in their parent's behavior (i.e., being stricter), as illustrated in Fig. 1.

In recent years, considerable theoretical steps have been taken in the study of how parenting affects adolescent (mal) adaptation. For example, apart from making a stronger theoretical divide between stable relative differences between families versus dynamic within-family processes (Darling and Steinberg 1993), it has been recognized that there is reciprocity (Pardini 2008), operation at different timescales (e.g., Branje 2018; Granic and Patterson 2006), and heterogeneity (e.g., Belsky and Pluess 2009) in these within-family parenting processes. Each of these theoretical concepts is explained in more detail below, as they are defining elements of the current review.

\section{Reciprocity in Parenting Processes}

It is acknowledged by several parenting theories that children are active agents in the within-family socialization processes (for an overview, see Pardini 2008). As one of the first, Bell (1968) described a continuous cycle of influences between parents and children, wherein both keep adapting to each other's behavior. Another well-known example is the coercion theory (Granic and Patterson 2006; Patterson 1982), which proposes a reciprocal cycle between maladaptive parenting and externalizing problem behavior. In this cycle, occurring at relatively short timescales, maladaptive parenting increases the externalizing problem behavior of the child, which in turn is followed by an increase in maladaptive parenting. If such feedback-patterns become stable negative cycles within a family, they could exacerbate the child's externalizing problem behavior in the long-term. Hence, these theories suggest that parenting entails an ongoing dynamic process between parenting and adolescent adaptation, which flows not only from parents to their children, but also from the children to their parents.

\section{Timescale of Parenting Processes}

Parenting processes, as described before, can unfold at different timescales. The coercion theory (Granic and Patterson 2006; Patterson 1982), suggests that processes at the micro timescale influence the development at the macro timescale, such that momentary hostile parent-child interactions influence the child's longer-term development of problem behavior (e.g., months or years). Conversely, macro-level development may also influence what happens at the every-day 
micro timescale (Granic and Patterson 2006; Smith and Thelen 2003). This mutual influence can be isomorphic when repeated micro-longitudinal effects translate to the gradual build-up of more persistent macro-longitudinal changes. However, effects can also be countervailing. For instance, prohibiting an adolescent from hanging out with friends on a given evening may effectively reduce adolescent delinquency that day. Nevertheless, through psychological processes of reactance (Brehm 1966) the child may develop a more rebellious life style in the longer-term (e.g., Keijsers et al. 2012). Thus, although most parenting theories do not explicitly postulate the timescale on which parenting processes may take place (but see Granic and Patterson 2006), macro theories in developmental psychology (e.g., dynamic systems theory; Smith and Thelen 2003) suggest that empirical studies need to assess varying timescales to capture the complex dynamic processes between parents and adolescents.

\section{Heterogeneity in Parenting Processes}

Recent theories have also started to challenge the universality of parenting processes. That is, they challenge whether adverse or beneficial effects of parenting on children's adaptation are similar in every family. For instance, dynamic systems theory posits that each system (e.g., parent-child dyad) is unique (Granic and Patterson 2006; Smith and Thelen 2003), implying that parent-adolescent dynamics may have unique characteristics in each family. Differences between families in their parenting processes may arise through (a) contextual differences, such as socioeconomic status (e.g., Rekker et al. 2017), as proposed by ecological theories (e.g., Bronfenbrenner 1986; Sameroff 2010), (b) individual differences in children's susceptibility to adverse and beneficial parenting due to personality differences and/or temperament (Belsky and Pluess 2009; Slagt et al. 2015), or (c) individual differences in children's appraisal of parenting practices or coping strategies (Soenens et al. 2015). Hence, based on these theoretical perspectives, the extent to which universal parenting principles exist can be challenged. To empirically address this challenge, the current review summarizes whether the existing studies tested for heterogeneity in within-family parenting processes, for instance through testing random slopes and/or explaining the random slopes by moderators.

\section{Studying Parenting Processes: Matching the Methodological Approach to the Research Question}

Conceptually, reciprocal, multi-timescale, and heterogeneous parenting processes are operationalized as associations between over-time fluctuations in parenting and adolescent adaptation within the same families (Darling and Steinberg 1993). For example, the internalizing problems of an adolescent might decrease after his or her own parent heightens their supportive behavior towards the adolescent, but also vice versa, in cases that adolescents' internalizing problems may erode parental support. Nonetheless, until recently, most studies have focused on relative differences between families (e.g., correlation, regression, standard cross-lagged panel model). In such between-family designs, a negative correlation between parental control and externalizing problems indicates that adolescents show less externalizing problem behavior in families in which parental control is higher compared to families in which parental control is lower (Pinquart 2017a).

Whether such estimates of relative differences between families can be used as a basis for theoretical inferences regarding parenting processes that occur within families is one of the ongoing discussions in the parenting literature and beyond (see Berry and Willoughby 2017; Hamaker 2012; Keijsers 2016; Molenaar 2004). One of the most recent insights is that drawing inferences about processes within families, without separating stable difference between families, might lead to less accurate conclusions about the magnitude and/or direction of within-family effects (Hamaker et al. 2015). To illustrate, a recent study by Dietvorst et al. (2018) found evidence of opposing effects between and within families. Comparing families, the authors found that families with higher average levels of adolescent secrecy also had higher average levels of parental privacy invasion compared to families with lower average levels of privacy invasion (positive association). However, when they analyzed the fluctuations within families, they found that in periods with higher levels of adolescent secrecy were followed by periods with lower levels of parental privacy invasion (negative time-lagged effect). In this case at least, if processes in families would be inferred from such betweenfamily findings, it would be mistakenly inferred that adolescents' increased secrecy might result in their parents becoming more invasive, whereas actually a reversed process was observed.

To avoid an ecological fallacy in the interpretation of empirical results when investigating within-family parenting processes, the theoretical question should match the level of analysis (i.e., between-family versus within-family level). When examining hypotheses about parenting processes occurring within families, the matching analytical level is the within-family level. For example, a longitudinal study might apply a multilevel approach that examines withinfamily effects by separating variance due to stable differences between families in their averages from variance due to the fluctuations around the families' own stable averages (e.g., Hamaker et al. 2015; Keijsers 2016). Thus, for research questions that explore dynamic family processes that are 
described by many theoretical perspectives on parenting, some of which are discussed below, the within-family level is the matching empirical level.

\section{The Current Study}

Previous studies on parenting have largely contributed to the understanding how families differ in parenting and adolescent adaptation. For example, these studies have demonstrated that adolescents show fewer internalizing problems in families with relatively high levels of support, compared to other families (Pinquart 2017b). However, parenting theories often describe dynamic processes, in which over-time fluctuations in parenting and adolescent adaptation are linked within the same family. To obtain an overview of the available peer-reviewed within-family studies on parenting and adolescent adaptation, a systematic search was conducted, after which the studies were summarized and discussed. Additionally, specific attention was paid to the aforementioned theoretical concerns of reciprocity, timescales of observation, and heterogeneity.

\section{Method}

\section{Search Strategy}

To assess all the published longitudinal within-family studies on parenting adolescents, eligible peer-reviewed articles were searched in October 2017 with no restriction on publication date. The following electronic databases were consulted: PsycINFO, PsycARTICLES, Psychological and Behavioral Sciences Collection, MEDLINE, Social Sciences Citation, and ERIC. Keywords were used pertaining to parenting, the age group, the ecological level, and the statistical approach. Hence, it was specified that titles, keywords, or abstracts should contain at least one keyword from each of these four categories:

(a) Parenting: parent*, family, caregiv*, mother, father, maternal, and paternal.

(b) Age group: adolescen*, teen, youth, middle school, high school, and secondary school.

(c) Ecological level: within- or intra- combined with individual, person, adolescent, youth, subject, participant, and family (e.g., within-individual or intra-participant). The terms idiograph*, person-specific, time-varying and single-subject were also used.

(d) Analysis: multilevel, random effect, random intercept, random slope, fixed effect, mixed model, hierarchical, and time series.
Moreover, additional studies were searched through scanning the reference lists of eligible studies and emailing experts ( 12 out of 17 responded) to ask for studies that were (conditionally) accepted. Researchers who were author of at least two eligible publications were considered experts. The search for eligible studies was completed in May 2018.

\section{Inclusion Criteria}

To be included in the review, studies had to meet the following criteria:

1. Parenting To provide a comprehensive summary of all the published studies on within-family parenting processes, studies were included that referred to parenting practices (e.g., monitoring and support), dyadic characteristics of the parent-adolescent relationship quality (e.g., closeness and conflict), and/or differential parenting (i.e., differential parental treatment compared to sibling in all parenting domains). Measures that did not exclusively tap into the processes between parents and their children, such as family conflict (i.e., level of conflict between all family members) or inter-parental conflict, were not included in the review.

2. Adolescent adaptation To obtain a comprehensive overview, various domains of functioning were included and thus there was no exclusion based on adolescent outcomes. Adolescents' interpersonal behavior towards their parents (e.g., disclosure) was labeled as adolescent adaptation and not as a parenting.

3. Sample Adolescence was defined as the period between 10 and 20 years to include studies conducted with late adolescents too. Because longitudinal studies can span a period of multiple years, it was decided to also include studies that carried out their first measurement wave in childhood ( $<10$ years) and followed children until adolescence.

4. Multivariate within-family effect of parenting and adolescent adaptation The study examined associations between within-family fluctuations in parenting and adolescent adaptation concurrently (e.g., a momentary higher level of $\mathrm{X}$ is associated with a momentary higher level of $\mathrm{Y}$ within the same family) and over time (e.g., a momentary higher level of $\mathrm{X}$ is associated with a momentary higher level at $t+1$ within the same family). The exclusive focus on within-family estimates required longitudinal data and the use of multilevel analyses with group-mean centering (i.e., centered around a family's own mean). Estimates of associations between slopes of multivariate growth curve models were excluded because they provide between-person associations of estimates of within-family mean level changes (e.g., families with an over-time increase in $\mathrm{X}$ show a stronger 
Fig. 2 Flowchart of systematic literature search

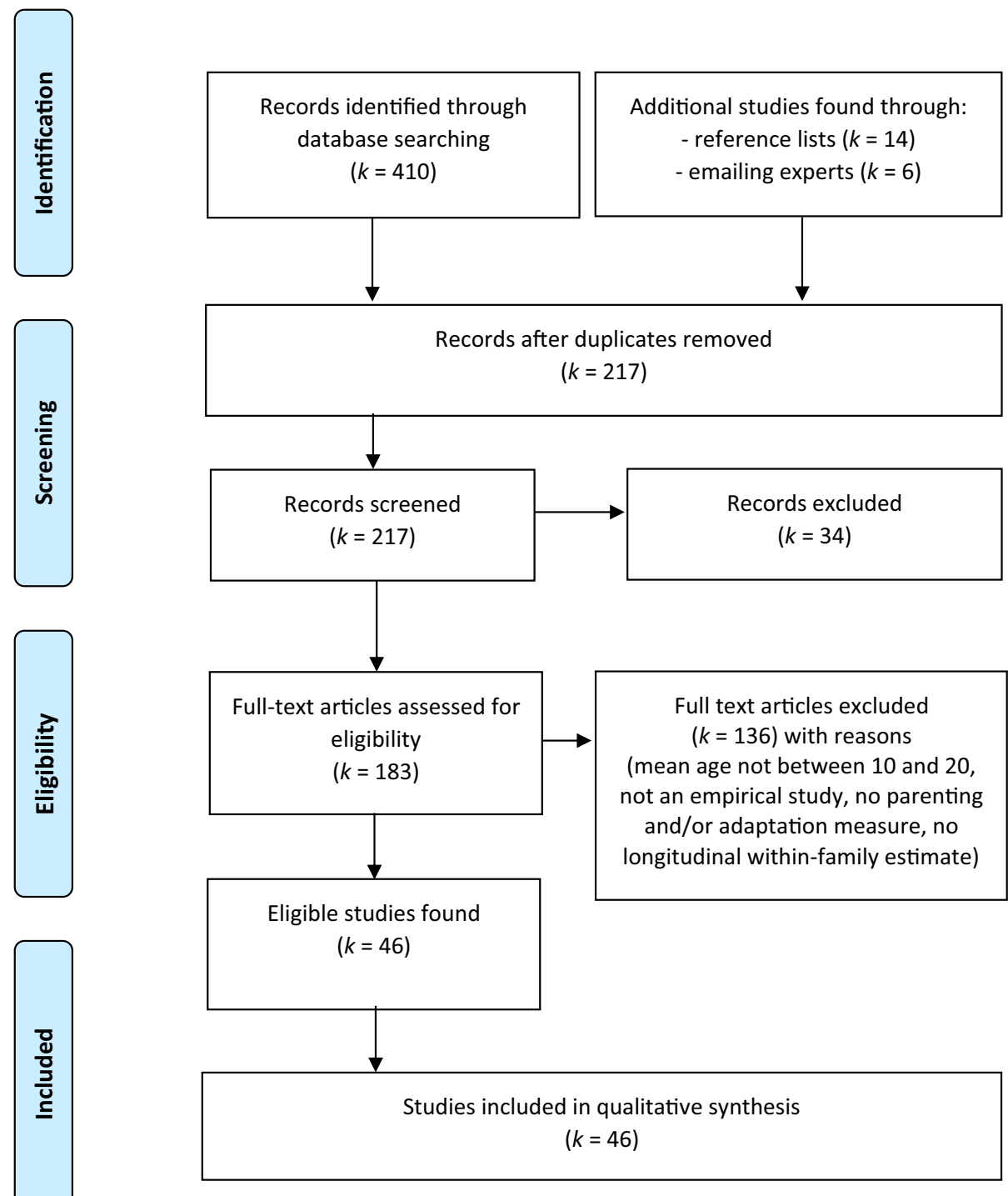

increase in $\mathrm{Y}$ compared to families with an over-time decrease in X) (see also Keijsers and Van Roekel 2018).

\section{Screening Eligible Studies}

The database search resulted in 197 unique studies (Fig. 2 outlines the search). Three raters independently screened the titles and abstracts. They retrieved the full text when a study was potentially eligible $(k=163)$. The inter-rater agreement between the first author (the first coder) and the PI of the project (the second coder) regarding eligibility was high at 95.9\% $(\kappa=.84)$. The ratings of the first author were also compared to a third coder, but this resulted in lower agreement because the third coder had limited experience with multilevel analyses $(89.3 \%$; $\kappa=.57)$. Disagreements were discussed until the three coders reached consensus. The authors of selected studies were contacted if the information necessary for the purpose of this study was not mentioned in their publication. In total, 26 studies of the database search were deemed eligible. An additional 14 eligible studies were found in the reference lists and six eligible studies were found through emailing experts and ResearchGate (Coley et al. 2009; Cox et al. 2018; Dietvorst et al. 2018; Gottfredson and Hussong 2011; Janssen et al. 2018; Janssen et al. 2017). Thus, the final selection comprised 46 studies.

\section{Coding of the Studies}

Sample and study characteristics were coded, such as sample size, mean age at $\mathrm{T} 1$, gender composition ( $\%$ male), ethnicity (ethnicity of majority of sample), socioeconomic status (SES; based on education and/or income), family structure (i.e., two- or single-parent, marital status), and the number of measurement waves. In line with earlier studies on parenting (e.g., McLeod et al. 2007; Pinquart 2017a), parenting was post hoc grouped according to the following dimensions: 
parental support (e.g., warmth, involvement, and attachment), parental control (e.g., punishment, supervision, and knowledge), negative interaction (e.g., conflict, hostility, and poor communication). Moreover, three coding categories were added, namely, time spent together (e.g., parental presence and joint involvement), parent-child relationship quality (i.e., overall quality or satisfaction, or composite scores of positive and negative indicators), and differential parenting (i.e., parental treatment compared to sibling). Indicators of adolescent adaptation were post hoc grouped into the following dimensions, representing key-dimensions in adolescent functioning (Achenbach and Edelbrock 1987): externalizing behavior (e.g., conduct problems, hyperactivity, and delinquency), internalizing behavior (e.g., depressive symptoms, low self-esteem), interpersonal functioning (e.g., disclosure to parents and peer problems), academic functioning (e.g., academic problems and successes), and physical functioning (e.g., physical activity and cortisol level). Additionally, because adolescent affective functioning (e.g., positive and negative mood) may be related to both internalizing and externalizing behavior (Maciejewski et al. 2019), it was coded as a separate category. Moreover, the type of statistical analysis was coded as fixed effects regression, multilevel regression models, multilevel growth models with time-varying effects, or multilevel structural equation models. The results were organized into concurrent (i.e., within-time point) or time-lagged effects, and the timelagged effects were further categorized in parent-to-adolescent and adolescent-to-parent effects. Furthermore, the time interval between measurement occasions was coded. Heterogeneity of within-family effects was assessed by the examination of random bivariate slopes and moderators that explained variation in the random slopes, either at Level 1 (the measurement) or Level 2 (the family).

\section{Results}

\section{Study and Sample Characteristics}

This review included 46 studies (for overview, see Table 1). An extended version of this table can be found in the online supplementary material (Online Resource 1), which also includes a summary of the findings of each study. The studies utilized two to 216 (median 4.5) measurement occasions. Of the 46 studies, 30 studies examined parenting processes at a macro timescale (time-interval of 6 months or longer), three studies at a meso timescale (i.e., intervals between weeks to months), and thirteen at a micro timescale (i.e., from seconds to days), adopting primarily a daily diary design $(k=10)$. See Fig. 3 for a graphical overview.

The sample sizes of the studies ranged from 39 to 22,909 $($ Mean $=1329$; median 409). Mean age during the first measurement wave ranged from 6.9 to 16.1 years (seven studies did not provide the exact mean age), and the percentage of males ranged from 0 to $100 \%(M=51 \%$; two studies did not provide the sample's gender distribution). Regarding ethnicity, most of the American and Canadian studies used samples of which the majority was European American ( $k=22$ out of 33) and all the Dutch studies used samples of which the majority was Dutch (expect for one study that did not report ethnicity). The other two remaining studies, a Korean and Belgium study, did not report ethnicity. Furthermore, a few studies used low SES samples, whereas the majority of studies had samples that were middle(-to-high) SES (for more details, see Online Resource 1). Moreover, almost all studies that reported about the family structure included two-parent (married) families. Only four studies had somewhat higher rates of single-parent families (between $32 \%$ and $40 \%$ ). Sexual orientation was not reported in the reviewed studies.

Several datasets were identified that were used in multiple studies: the National Longitudinal Survey of Youth 1997 (Chung et al. 2009; Coley et al. 2009; Coley et al. 2008), the Pittsburgh Youth Study (Besemer et al. 2016; Farrington et al. 2002; Rekker et al. 2015), the Research on Adolescent Development and Relationships (Keijsers et al. 2016; Rekker et al. 2017), the Study of Peers, Activities and Neighborhoods (Janssen et al. 2018; Janssen et al. 2014; Janssen et al. 2016; Janssen et al. 2017; Svensson et al. 2017), and The Work, Family, Health Network Study (Lippold et al. 2016a, b). Moreover, based on authors and sample characteristics, two unnamed datasets were identified that were assessed in multiple studies, a daily diary dataset (Bai et al. 2017; Kuhlman et al. 2016; Robles et al. 2016) and macro timescale study (Lam et al. 2016; Lam and McHale 2015).

\section{Findings Organized by Parenting Dimension}

Tables 2 and 3 provide an overview of the number of nonsignificant and significant concurrent and time-lagged associations between parenting and adolescent adaptation dimensions.

\section{Parental Support}

Fourteen studies examined links between parental support and adolescent adaptation within families, with six assessing adolescents externalizing behavior on a macro timescale. In three of the six studies, an increase in parental support was linked to a simultaneous decrease in externalizing behavior (Gottfredson et al. 2017; Meldrum et al. 2012; Svensson et al. 2017). One study also reported a similar time-lagged association, indicating that an increase in parental support was followed by an increase in adolescent self-control (Meldrum et al. 2012). However, another study found that an 


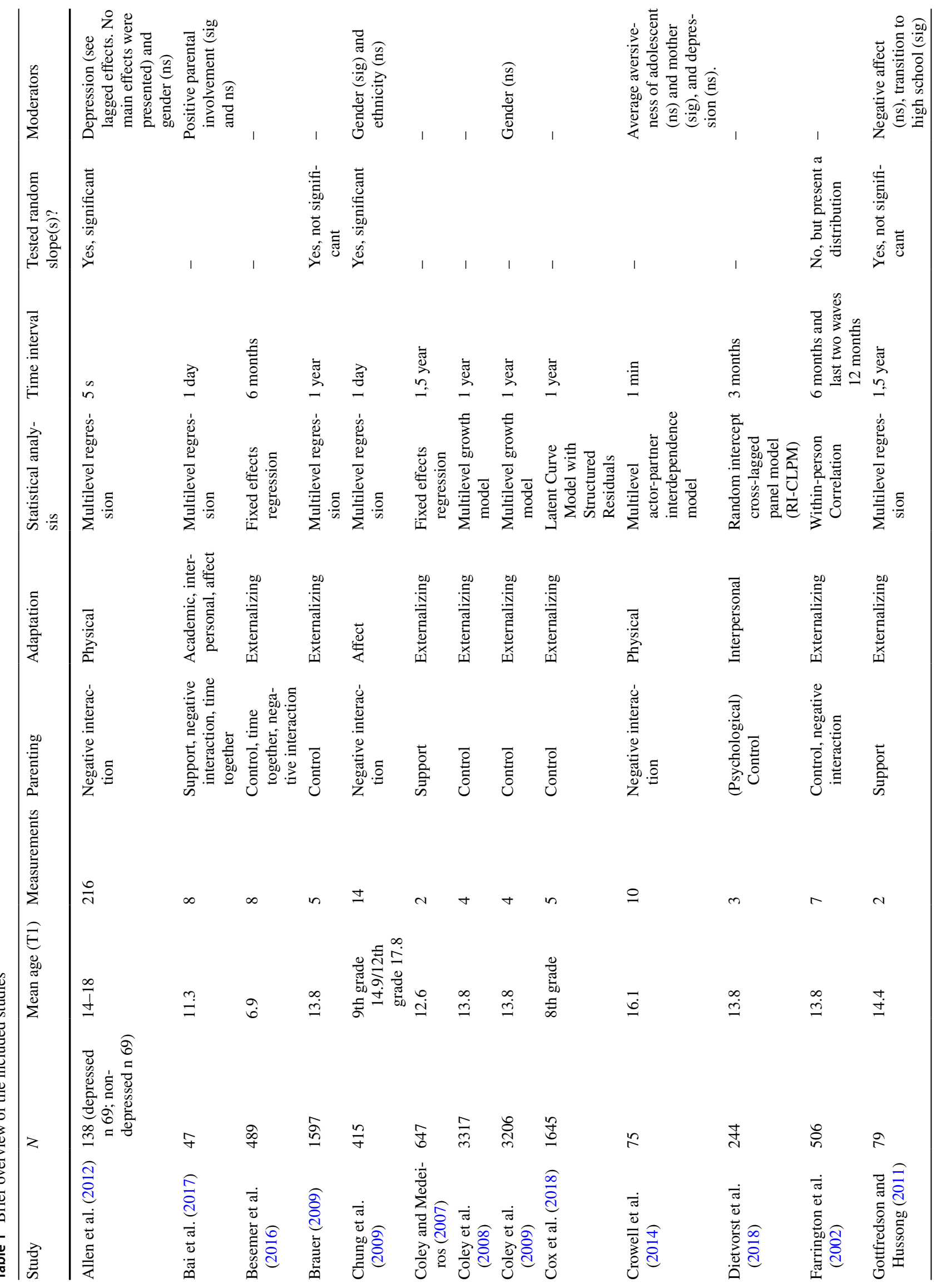




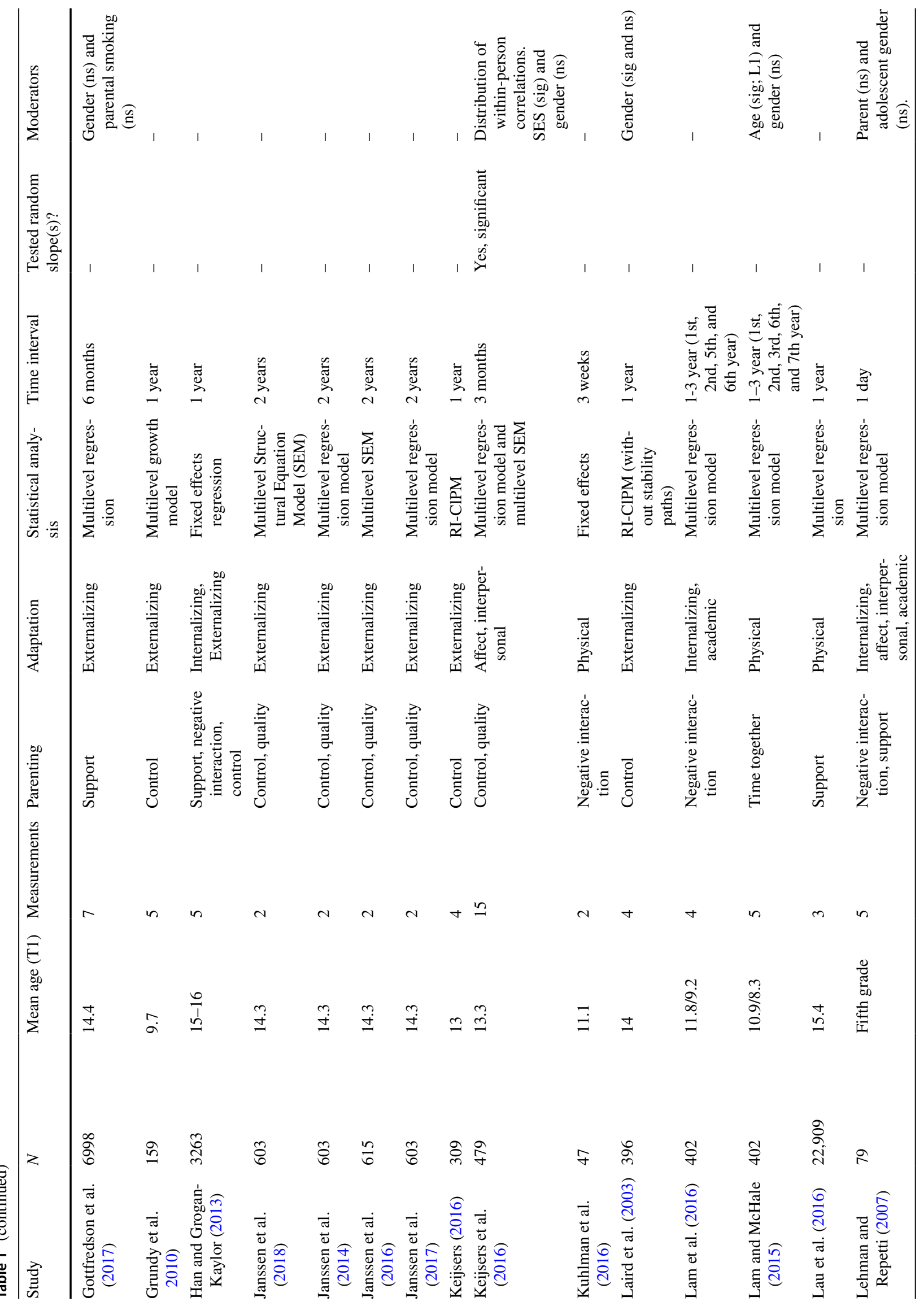




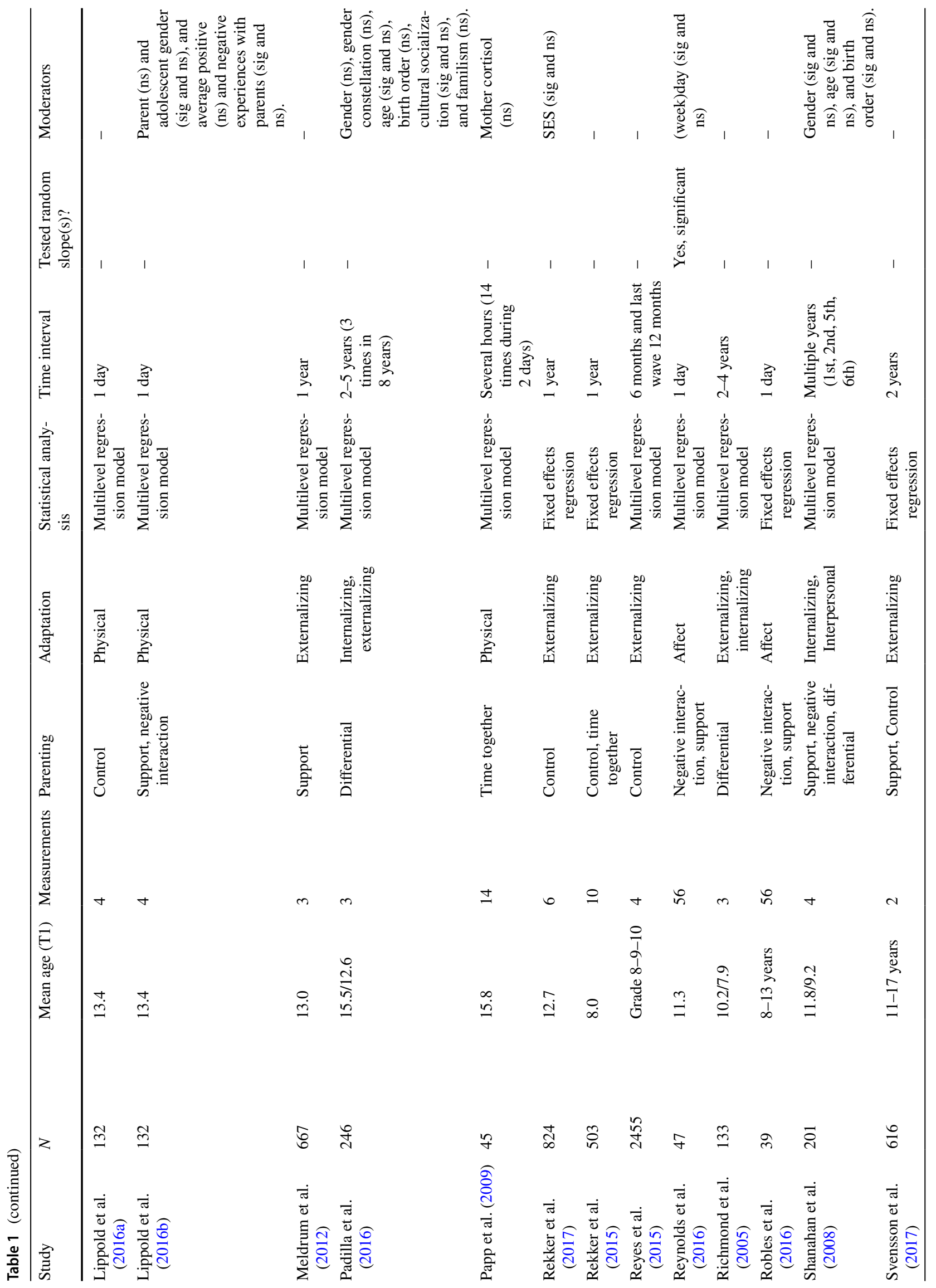


326

Adolescent Research Review (2020) 5:317-339

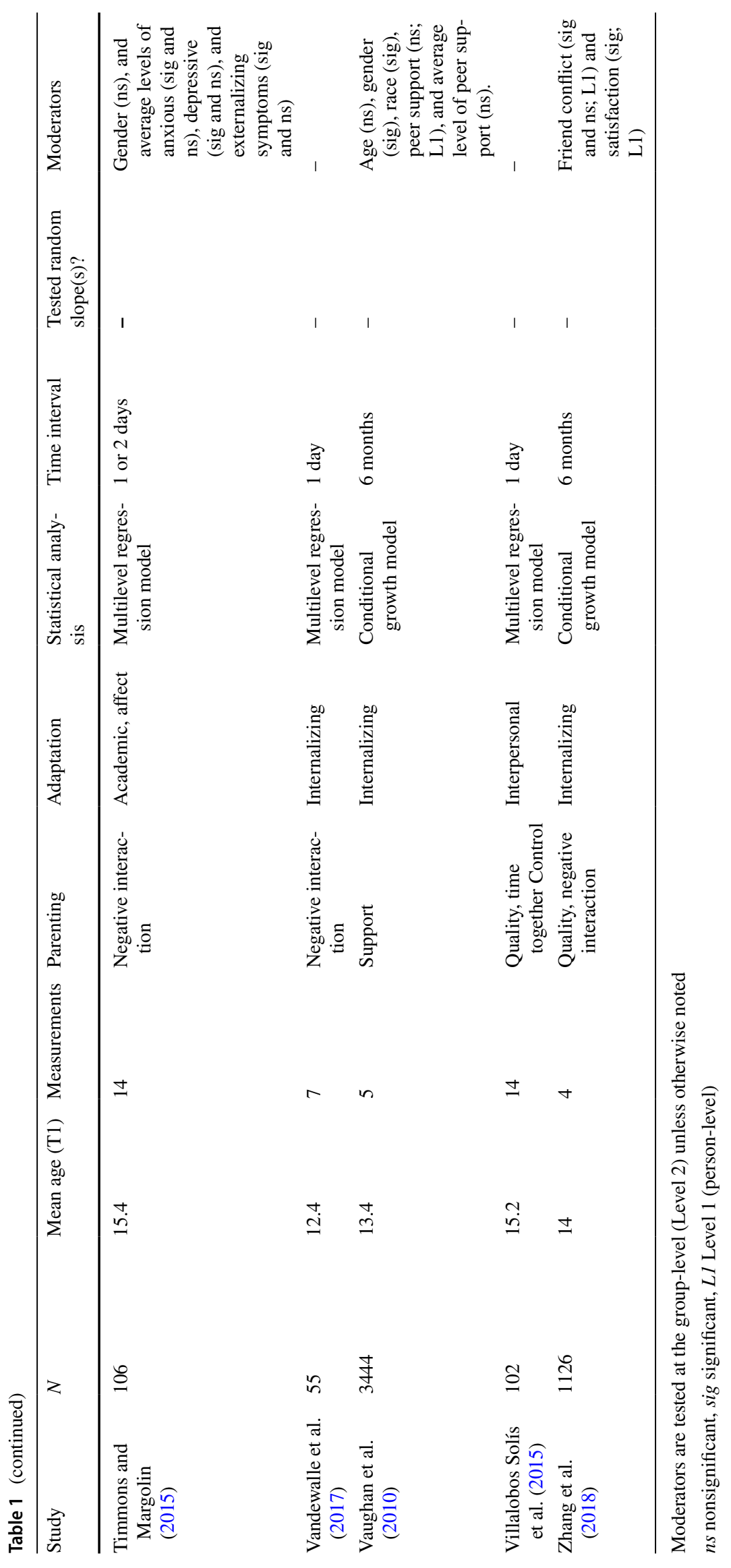

Springer 
Fig. 3 Frequency of the time intervals between measurement occasions of included studies

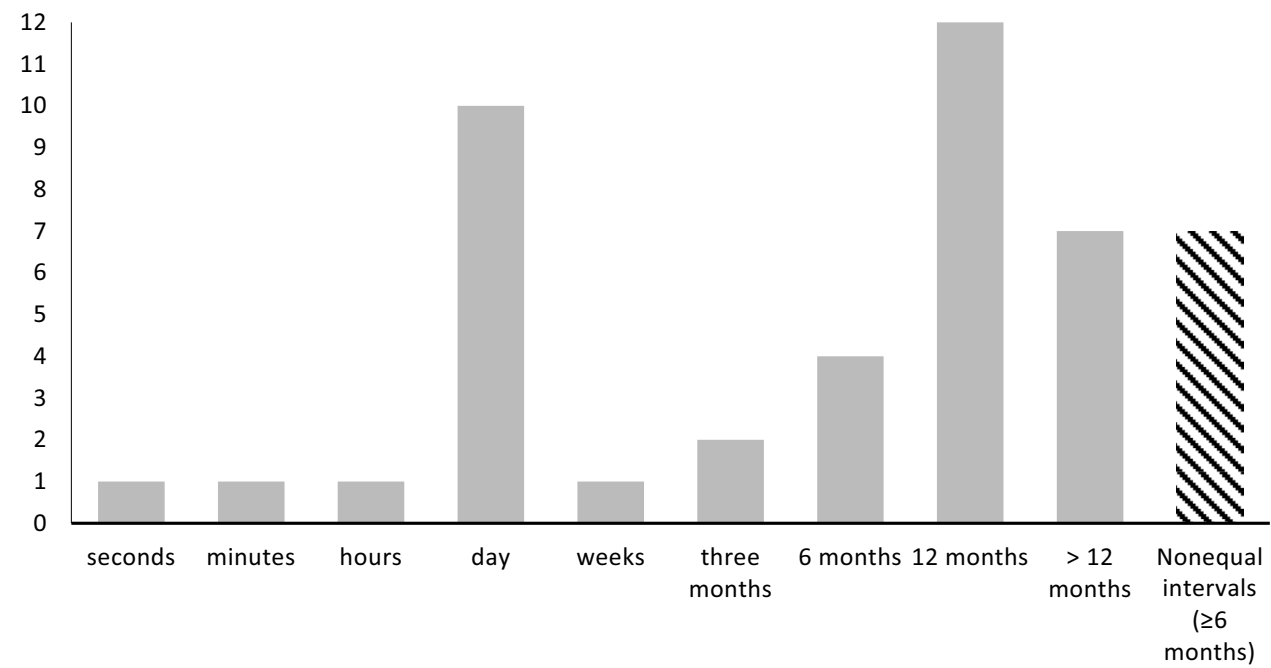

increase in parental support was related to a simultaneous increase in adolescent externalizing behavior (Coley and Medeiros 2007). Additionally, Gottfredson and Hussong (2011) found no significant concurrent or lagged associations of parental support with several indicators of externalizing behavior. Thus, macro-longitudinal within-family studies on parental support and adolescent externalizing behavior together showed a somewhat inconsistent picture while studies on micro timescales were missing.

Three of the 14 studies investigated the within-family link between parental support and internalizing behavior, all on a macro timescale. The findings suggested that adolescents reported more parental support at times they reported higher levels of internalizing behavior (Han and Grogran-Kaylor 2012). When support of mothers and fathers were examined separately, the results showed again a negative concurrent association for maternal support (Shanahan et al. 2008; Vaughan et al. 2010) but not for paternal support (Shanahan et al. 2008). Hence, these findings provided evidence of a negative concurrent link between parental support and internalizing behavior at a macro timescale, but this evidence seems to be stronger for maternal support than for paternal support.

Four of the 14 studies examined associations of parental support with measures of adolescent affective functioning within families, and three of the four studies analyzed the same daily diary dataset. These three studies indicated that the levels of parental support were higher on days when adolescents also reported a more positive mood (Robles et al. 2016) and a less negative mood (Bai et al. 2017; Reynolds et al. 2016). The fourth study, which was again a daily diary study, did not find a concurrent association of parental support with adolescents' anxious mood (Lehman and Repetti 2007).

The remaining studies on parental support investigated the associations with a wide range of measures of interpersonal, academic, and physical functioning within families. With respect to interpersonal functioning, micro-longitudinal studies found no concurrent association of parental support with peer problems (Bai et al. 2017; Lehman and Repetti 2007). A macro-longitudinal study, in contrast, suggested that increasing levels of maternal (but not paternal) warmth were related to simultaneous increases in sibling warmth (Shanahan et al. 2008). Concerning academic functioning, both positive significant and nonsignificant concurrent associations were found between parental support and academic functioning (Bai et al. 2017; Lehman and Repetti 2007). Moreover, two studies considered physical functioning, finding that parental support was not related to physical functioning at the micro timescale (Lippold et al. 2016b), but increasing levels of parental support regarding physical activity were at the same time related to more physical activity at the macro timescale (Lau et al. 2016). Thus, the five remaining studies that assessed various adaptation measures suggested that associations might vary between timescales.

\section{Parental Control}

Twenty-two studies examined the link between parental control and adolescent adaptation within families, of which 18 assessed externalizing behavior on a macro timescale. The results of several studies suggested that higher levels of parental control were simultaneously related to lower levels of externalizing behavior (Grundy et al. 2010; Janssen et al. 2018, 2014, 2016; Laird et al. 2003; Rekker et al. 2015; Svensson et al. 2017). However, studies have also found the opposite pattern. For example, parental control was higher in low-SES families (but not high-SES families) when adolescent delinquency was higher (Rekker et al. 2017). Additionally, an increase in adolescent risky sexual behavior predicted a subsequent increase in paternal knowledge (Coley et al. 2009). Moreover, a large number of studies reported 
Table 2 Overview of the concurrent associations between parenting and adolescent adaptation dimensions

\begin{tabular}{|c|c|c|c|c|c|c|c|c|c|c|c|c|c|c|}
\hline \multirow[t]{3}{*}{ Parenting dimension } & \multirow[t]{3}{*}{ Finding } & \multicolumn{13}{|c|}{ Adolescent Adaptation Dimension } \\
\hline & & \multicolumn{2}{|c|}{$\begin{array}{l}\text { Externalizing } \\
\text { behavior }\end{array}$} & \multicolumn{2}{|c|}{$\begin{array}{l}\text { Internalizing } \\
\text { behavior }\end{array}$} & \multicolumn{2}{|c|}{$\begin{array}{l}\text { Negative } \\
\text { affect }\end{array}$} & \multicolumn{2}{|c|}{$\begin{array}{l}\text { Interpersonal } \\
\text { functioning }\end{array}$} & \multicolumn{2}{|c|}{$\begin{array}{l}\text { Academic } \\
\text { functioning }\end{array}$} & \multicolumn{2}{|c|}{$\begin{array}{l}\text { Physical } \\
\text { functioning }\end{array}$} & \multirow[t]{2}{*}{ Total $k$} \\
\hline & & E & $k$ & E & $k$ & E & $k$ & E & $k$ & E & $k$ & $\mathrm{E}$ & $k$ & \\
\hline \multirow[t]{4}{*}{ Support } & $\uparrow$ & 1 & 1 & & & & & 1 & 1 & 1 & 1 & 3 & 1 & $13(11)$ \\
\hline & ns & 1 & 1 & 1 & 1 & 1 & 1 & 9 & 3 & 7 & 2 & 5 & 2 & \\
\hline & $\downarrow$ & 8 & 3 & 4 & 3 & 6 & 3 & & & & & & & \\
\hline & Total & & $5(5)$ & & $3(3)$ & & $4(2)$ & & $3(3)$ & & $2(2)$ & & $2(2)$ & \\
\hline \multirow[t]{4}{*}{ Control } & $\uparrow$ & 1 & 1 & & & & & 5 & 2 & - & & 1 & 1 & $17(10)$ \\
\hline & ns & 23 & 12 & 1 & 1 & & & 3 & & & & 4 & 1 & \\
\hline & $\downarrow$ & 13 & 7 & 1 & 1 & 1 & 1 & & 2 & & & & & \\
\hline & Total & & $14(8)$ & & 1 & & 1 & & $2(2)$ & & & & 1 & \\
\hline \multirow[t]{4}{*}{ Negative interaction } & $\uparrow$ & 2 & 2 & 6 & 5 & 12 & 6 & & & & & & & $15(12)$ \\
\hline & ns & 3 & 1 & 2 & 2 & 2 & 2 & 8 & 2 & 6 & 2 & 4 & 2 & \\
\hline & $\downarrow$ & & & & & & & 2 & 1 & 6 & 3 & 1 & 1 & \\
\hline & Total & & $3(2)$ & & $6(6)$ & & $6(4)$ & & $3(3)$ & & $4(4)$ & & $2(2)$ & \\
\hline \multirow[t]{4}{*}{ Time spent together } & $\uparrow$ & 1 & 1 & - & & 1 & 1 & 1 & 1 & 1 & 1 & 3 & 2 & $6(5)$ \\
\hline & ns & 4 & 2 & & & & & 7 & 2 & 1 & 1 & & & \\
\hline & $\downarrow$ & 1 & 1 & & & & & & & & & & & \\
\hline & Total & & $2(1)$ & & & & 1 & & $2(2)$ & & 1 & & $2(2)$ & \\
\hline \multirow[t]{4}{*}{ Relationship quality } & $\uparrow$ & & & 1 & 1 & - & & 5 & 2 & - & & - & & $7(4)$ \\
\hline & ns & & & & & & & 3 & 1 & & & & & \\
\hline & $\downarrow$ & 6 & 4 & & & & & & & & & & & \\
\hline & Total & & $4(1)$ & & 1 & & & & $2(2)$ & & & & & \\
\hline \multirow[t]{4}{*}{ Differential parenting } & $\uparrow$ & 4 & 2 & 6 & 3 & - & & & & - & & - & & $3(3)$ \\
\hline & ns & 2 & 1 & 4 & 2 & & & & & & & & & \\
\hline & $\downarrow$ & & & & & & & 4 & 1 & & & & & \\
\hline & Total & & $2(2)$ & & $3(3)$ & & & & 1 & & & & & \\
\hline Total $k$ & & $19(13)$ & & $9(9)$ & & $7(5)$ & & $5(5)$ & & $4(4)$ & & $6(5)$ & & \\
\hline
\end{tabular}

A negative association for externalizing behavior, internalizing behavior, and negative affect indicates that a higher score on the parenting dimension was related to better adaptation (e.g., more parental support, less delinquency). A negative association with interpersonal, academic, and physical functioning indicates that a higher score on the parenting dimension is related to poorer adaptation (e.g., less parental support, more delinquency). A higher score on differential parenting is not in favor of the adolescent (e.g., sibling received more emotional support than the adolescent)

Total number between brackets is number of unique samples

$\uparrow$ positive association, $\downarrow$ negative association, $n s$ nonsignificant association, $E$ number of effects. $k$ number of studies

nonsignificant concurrent and time-lagged associations of parental control with various externalizing behaviors, such as aggression and delinquency (Besemer et al. 2016; Brauer 2009; Coley et al. 2008, 2009; Cox et al. 2018; Farrington et al. 2002; Han and Grogan-Kaylor 2013; Janssen et al. 2014, 2016, 2017, 2018; Keijsers 2016; Rekker et al. 2017, 2015; Reyes et al. 2015). Thus, although many included studies assessed within-family associations between parental control and adolescent externalizing behavior, the results showed mixed findings, even within the same studies and datasets.

Five out of the 22 studies addressed the within-family association of parental control with several adaptation domains. No concurrent association was found between parental knowledge and internalizing behavior on a macrolongitudinal scale (Han and Grogan-Kaylor 2013). Moreover, three studies assessed interpersonal functioning, with adolescent and/or secrecy in particular. Two of these studies applied a meso timescale ( 3 months) and reported that higher levels of maternal knowledge and solicitation, but not maternal control, were related to higher concurrent levels of adolescent disclosure (Keijsers et al. 2016), and higher levels of adolescent secrecy were followed by a lagged increase in parent's privacy invasion but not vice versa (Dietvorst et al. 2018). A micro-longitudinal study 
Table 3 Overview of the time-lagged associations between parenting and adolescent adaptation dimensions

\begin{tabular}{|c|c|c|c|c|c|c|c|c|c|c|c|c|c|c|}
\hline \multirow[t]{3}{*}{ Parenting dimension } & \multirow[t]{3}{*}{ Finding } & \multicolumn{13}{|c|}{ Adolescent adaptation dimension } \\
\hline & & \multicolumn{2}{|c|}{$\begin{array}{l}\text { Externalizing } \\
\text { behavior }\end{array}$} & \multicolumn{2}{|c|}{$\begin{array}{l}\text { Internal- } \\
\text { izing } \\
\text { behavior }\end{array}$} & \multicolumn{2}{|c|}{$\begin{array}{l}\text { Negative } \\
\text { affect }\end{array}$} & \multicolumn{2}{|c|}{$\begin{array}{l}\text { Interpersonal } \\
\text { functioning }\end{array}$} & \multicolumn{2}{|c|}{$\begin{array}{l}\text { Academic } \\
\text { functioning }\end{array}$} & \multicolumn{2}{|c|}{$\begin{array}{l}\text { Physical func- } \\
\text { tioning }\end{array}$} & \multirow[t]{2}{*}{ Total $k$} \\
\hline & & E & $k$ & $\mathrm{E}$ & $k$ & $\mathrm{E}$ & $k$ & $\mathrm{E}$ & $k$ & $\mathrm{E}$ & $k$ & $\mathrm{E}$ & $k$ & \\
\hline \multirow[t]{4}{*}{ Support } & $\uparrow_{\text {lag }}$ & & & - & & - & & - & & - & & - & & 1 \\
\hline & $\mathrm{ns}_{\text {lag }}$ & & & & & & & & & & & & & \\
\hline & $\downarrow_{\text {lag }}$ & 1 & 1 & & & & & & & & & & & \\
\hline & Total & & & & & & & & & & & & & \\
\hline \multirow[t]{4}{*}{ Control } & $\uparrow_{\text {lag }}$ & 1 & 1 & - & & - & & & & - & & - & & $8(7)$ \\
\hline & $\mathrm{ns}_{\text {lag }}$ & 23 & 5 & & & & & 7 & 2 & & & & & \\
\hline & $\downarrow_{\text {lag }}$ & 4 & 1 & & & & & 1 & 1 & & & & & \\
\hline & Total & & $6(5)$ & & & & & & $2(2)$ & & & & & \\
\hline \multirow[t]{4}{*}{ Negative interaction } & $\uparrow_{\text {lag }}$ & & & - & & & & - & & & & 3 & 1 & $4(4)$ \\
\hline & $\mathrm{ns}_{\text {lag }}$ & 6 & 1 & & & 2 & 1 & & & 3 & 1 & 8 & 2 & \\
\hline & $\downarrow_{\text {lag }}$ & & & & & & & & & 3 & 1 & 1 & 1 & \\
\hline & Total & & 1 & & & & 1 & & & & 1 & & $2(2)$ & \\
\hline \multirow[t]{4}{*}{ Time spent together } & $\uparrow_{\text {lag }}$ & & & - & & - & & & & - & & - & & $2(2)$ \\
\hline & $\mathrm{ns}_{\text {lag }}$ & 6 & 1 & & & & & 6 & 1 & & & & & \\
\hline & $\downarrow_{\text {lag }}$ & & & & & & & & & & & & & \\
\hline & Total & & 1 & & & & & & 1 & & & & & \\
\hline \multirow[t]{4}{*}{ Relationship quality } & $\uparrow_{\text {lag }}$ & - & & - & & - & & & & - & & - & & 1 \\
\hline & $\mathrm{ns}_{\text {lag }}$ & & & & & & & 6 & 1 & & & & & \\
\hline & $\downarrow_{\text {lag }}$ & & & & & & & & & & & & & \\
\hline & Total & & & & & & & & 1 & & & & & \\
\hline \multirow[t]{4}{*}{ Differential parenting } & $\uparrow_{\text {lag }}$ & - & & - & & - & & - & & - & & - & & 0 \\
\hline & $\mathrm{ns}_{\text {lag }}$ & & & & & & & & & & & & & \\
\hline & $\downarrow_{\text {lag }}$ & & & & & & & & & & & & & \\
\hline & Total & & & & & & & & & & & & & \\
\hline Total $k$ & & $7(5)$ & & 0 & & 1 & & $2(2)$ & & 1 & & 2 & & \\
\hline
\end{tabular}

A negative association for externalizing behavior, internalizing behavior, and negative affect indicates that a higher score on the parenting dimension was related to better adaptation (e.g., more parental support, less delinquency). A negative association with interpersonal, academic, and physical functioning indicates that a higher score on the parenting dimension is related to poorer adaptation (e.g., less parental support, more delinquency). A higher score on differential parenting is not in favor of the adolescent (e.g., a sibling received more emotional support than the adolescent)

Total number between brackets is number of unique samples

$\uparrow$ positive association, $\downarrow$ negative association, $n s$ nonsignificant association, $E$ number of effects, $k$ number of studies

again suggested that on days when adolescents reported higher levels of maternal solicitation they also reported higher levels of secrecy, but no lagged effects were found between maternal solicitation and adolescent secrecy (Villalobos Solís et al. 2015). Finally, regarding physical functioning, on days when adolescents reported higher levels of parental knowledge, they also had higher cortisol levels before dinner but not at other times of the day (Lippold et al. 2016a). However, because of the relative scarcity of empirical studies examining parental control in relation to other adaptation dimensions than externalizing behavior, most findings have yet to be replicated.

\section{Negative Parent-Child Interaction}

Seventeen studies assessed a within-family association between negative parent-child interaction and adolescent adaptation. Three studies focused on externalizing behavior on a macro timescale and reported mixed findings. Specifically, more negative parent-child interaction were related to more concurrent externalizing behavior (Farrington et al. 2002; Han and Grogan-Kaylor 2013). However, other studies found no concurrent or lagged associations with a variety of externalizing problem behaviors (Besemer et al. 2016). The six studies concerning internalizing behavior, both on daily and macro-longitudinal processes, showed more consistent 
results. Overall, the results of most studies suggested that poorer parent-child interactions were concurrently linked to more internalizing problems, such as depressive symptoms, lower self-esteem, and emotional eating (Han and GroganKaylor 2013; Lam et al. 2016; Lehman and Repetti 2007; Shanahan et al. 2008; Vandewalle et al. 2017; Zhang et al. 2018). Nonetheless, also some nonsignificant concurrent links were found between parental hostility and self-esteem (Han and Gorgan-Kaylor 2013), and parent-child conflict about homework and depressive symptoms (Lam et al. 2016).

Similarly as with internalizing behavior, micro-longitudinal studies on negative affect suggested that on days adolescents reported more conflicts with their parents, they reported more negative affect (Bai et al. 2017; Chung et al. 2009; Reynolds et al. 2016; Robles et al. 2016; Timmons and Margolin 2015). However, father-child conflict and negative affect (Reynolds et al. 2016) and aversive parental behavior and adolescents' anxious morning mood (Lehman and Repetti 2007) were not found to be concurrently related, and no time-lagged effects of parent-child conflict on adolescent-reported negative affect have been found (Timmons and Margolin 2015).

Moreover, two within-family studies on negative parentchild interaction have been conducted with interpersonal functioning and four with academic functioning. Concerning interpersonal functioning, the studies show that negative parent-child interaction was not concurrently associated with peer problems (Lehman and Repetti 2007) but was concurrently associated with increases in sibling conflict at the macro timescale (Shanahan et al. 2008). Moreover, regarding academic functioning, three micro-longitudinal studies suggested that adolescents reported more academic problems on days with poorer parent-child interaction (Bai et al. 2017; Lehman and Repetti 2007; Timmons and Margolin 2015), and an increase in academic problems was related to poorer parent-child interaction the next day, but not vice versa (Timmons and Margolin 2015). However, a macrolongitudinal study on school performance (i.e., grades) did not find significant concurrent associations with academic functioning (Lam et al. 2016). Hence, so far, there is some preliminary evidence that academic problems might be related to negative parent-child interaction on a micro timescale, but insufficient evidence is available with respect to the macro timescale.

Four studies assessed the relationship between negative parent-child interactions and physical functioning, all on a micro timescale. In observed interactions, increased father's anger and decreased father's dysphoria predicted increases in the adolescent's heart rate a few seconds later in depressed adolescents but not in non-depressed adolescents. However, in non-depressed adolescents (but not in depressed adolescents) increased mother's anger predicted decreased the adolescent's heart rate a few seconds later (Allen et al. 2012). Moreover, maternal aversive behavior that was rated every minute for 10 min was unrelated to the adolescent's respiratory sinus arrhythmia reactivity (Crowell et al. 2014). At a daily level, adolescents reported poorer parent-child interaction on days when they also reported more physical health symptoms, such as headaches and allergies. Negative parent-child interaction did not co-vary with adolescents' daily cortisol levels or measures at 3-weekly intervals (Kuhlman et al. 2016; Lippold et al. 2016b). Thus, the studies reviewed here indicated within-family associations of negative parent-child interaction with adolescents' heart rate and physical symptoms but not with cortisol levels.

\section{Time Spent Together}

Six studies have investigated the link between time spent together with parents and adolescent adaptation within families, each of them using a different measure of adolescent adaptation. Starting with the macro timescale, Rekker et al. (2015) found that adolescents reported more time spent with parents during periods in which they reported less externalizing behavior (i.e., minor delinquency). However, Besemer et al. (2016) revealed that adolescents showed higher levels of externalizing behavior simultaneously when they spent more time with parents. Moreover, more time spent together has been linked to increased levels in adolescents' physical activity (Lam and McHale 2015). Concerning the micro timescale, adolescents had lower cortisol levels at times their mother was present (Papp et al. 2009), and adolescents reported spending more time with their mother on days that they reported more disclosure about personal behavior, but not bad behavior or secrecy about personal or bad behavior (no time-lagged effects were found; Villalobos Solís et al. 2015). Additionally, on days adolescents spent more time with their father, they reported fewer academic problems but not peer problems (Bai et al. 2017). Hence, these six studies cautiously suggested that more time spent with parents predicts better adaptation in adolescents at the within-family level.

\section{Parent-Child Relationship Quality}

Seven studies focused on parent-child relationship quality, four of which assessed its association with externalizing behaviors within-families - all using the same dataset with macro time intervals. These studies found that at times during which adolescents reported a higher parent-child relationship quality, they also reported less externalizing behavior (Janssen et al. 2018, 2014, 2016, 2017). The other three studies assessed the within-family link of parent-child relationship quality with several adaptation dimensions, indicating that higher relationship quality was concurrently 
related to less internalizing behavior (Zhang et al. 2018), less negative affect (Keijsers et al. 2016), and better interpersonal functioning such that they were more open to their parents (Keijsers et al. 2016; Villalobos Solís et al. 2015).

\section{Differential Parenting}

Three studies assessed concurrent within-family links of differential parenting (i.e., differential treatment of siblings). The parental treatment was different in respect to negative interaction and support (Padilla et al. 2016; Shanahan et al. 2008) or control (Richmond et al. 2005) and these differences (rather than the absolute levels of parenting) were linked to adolescent adaptation on a macro timescale. Two studies that focused on the link with externalizing behavior suggested that increases in differential parenting co-varied with simultaneous increases in adolescents' externalizing behavior at the within-family level (Richmond et al. 2005). When differential parenting of mothers and fathers was examined separately, an increase in differential parenting of the father, but not of the mother, was concurrently associated with an increase in the adolescent's externalizing behavior (Padilla et al. 2016).

All three within-family studies on differential parenting assessed a link with internalizing behavior. Richmond et al. (2005) found that the oldest sibling (but not the youngest) reported more differential parenting at times they also reported more internalizing behavior. Another study suggested that adolescents reported higher levels of maternal and paternal differential parenting in terms of both support and negative interaction at times they also reported more internalizing behavior (Shanahan et al. 2008). However, this was not replicated by Padilla et al. (2016), who found that only increases in maternal differential treatment in support were related to concurrent increases in internalizing behavior within families, but not paternal differential support or maternal/paternal differential negative interaction. Thus, only a handful of longitudinal studies have assessed concurrent associations between differential parenting and externalizing and internalizing behavior within families. Even though some effects have been replicated, the results seem to depend on varying factors (youngest vs. oldest sibling and mother vs. father).

\section{Heterogeneity in Within-Family Associations}

The third key element of this review is the aspect of heterogeneity in the within-family effects. That is, do the withinfamily estimates vary between families or within the same families? To investigate this, it was coded whether studies estimated variance around the slopes of the bivariate associations as well as whether studies included a moderator of the within-family estimates. Although twenty studies assessed moderators, only six studies mentioned the variation around the within-family estimates. Four of them reported a significant variation (Allen et al. 2012; Chung et al. 2009; Keijsers et al. 2016; Reynolds et al. 2016), indicating heterogeneity in the within-family effects, and two studies did not find variation in the within-family association (Brauer 2009; Gottfredson and Hussong 2011). In addition, some authors reported problems in the statistical estimation of variation around the effects (Lehman and Repetti 2007; Reynolds et al. 2016).

Moderation effects (for an overview of examined moderators, see Table 1) were mostly assessed at the betweenfamily level by investigating how the within-family associations differed between families, and these moderators typically included adolescent, parental, and family characteristics. Most studies assessed adolescent characteristics, focusing on demographic factors (i.e., gender, age, birth order, ethnicity, and race). For example, Chung et al. (2009) found that girls experienced more distress on days on which they had more conflicts with their parents compared to boys. A limited number of studies also considered adolescent psychopathology, such as depressive, anxiety, and externalizing symptoms. For instance, Timmons and Margolin (2015) found that adolescents with more depressive or anxiety symptoms reported a more negative mood on days on which they had more conflicts with their parents compared to adolescents with fewer depressive or anxiety symptoms.

Regarding parent characteristics, gender, average levels of parenting behaviors, substance use, and physical functioning were studied. One finding suggested, for example, that only adolescents with highly involved mothers (and not adolescents with less involved mothers) reported more academic problems on days on which they reported less maternal support (Bai et al. 2017). Furthermore, a broader perspective was taken by examining family characteristics, including socioeconomic status, family values, and cultural socialization. For instance, the study of PadillaWalker et al. (2016) did not find evidence for a moderating effect of familism values in the within-family associations between differential parenting and adolescent externalizing or internalizing behavior. In addition to moderators at the between-family level, a limited number of studies assessed moderators at the within-family level, explaining how associations might differ within the same families, and these moderators typically involved peer functioning and time. For instance, the association between parentchild conflict and depressed adolescents' mood was found to be stronger on days when friend satisfaction was low rather than high (Zhang et al. 2018). Thus, at this point, various moderators have been tested, although mainly at the between-family level. 


\section{Discussion}

Responding to the call for empirical studies to assess how fluctuations in parenting may lead to fluctuations in their own adolescent's adaptation (Keijsers 2016; Meeus 2016; Rote and Smetana 2018), the current systematic review synthesized peer-reviewed studies on within-family associations between parenting and adolescent adaptation. While both between-family studies and within-family studies are necessary to grasp the complex reciprocal links between parenting and adolescent adaptation, the current review highlighted that the number of within-family parenting studies was strikingly limited: Only 46 compared to the hundreds of studies included in the meta-analyses at the between-family level (e.g., Pinquart 2017a). In the following section, some first insights are identified into whether children are better adapted in or following periods when their own parents are, for instance, more supportive and controlling. Following this, the limitations and caveats of the included studies are evaluated and directions for within-family studies are provided.

\section{Parenting Processes on Adaptation Dimensions: What Do We Know So Far?}

Most studies investigated at least one of the parenting dimensions control $(k=22)$, negative interaction $(k=17)$, and support $(k=14)$. Regarding adolescent adaptation, the dimension externalizing behavior $(k=24)$ was the most popular outcome variable. Especially the link between parental control and adolescent externalizing behavior was frequently studied $(k=18)$, although a fair amount of these studies analyzed the same dataset. The results of these studies, of which most of them were concurrent associations and all on a macro timescale, provided some first pieces of evidence that adolescents displayed fewer externalizing problems in years when their own parents were also more controlling or monitoring more intensively. However, in contrast to key parenting theories (Patterson 1982; Stattin and Kerr 2000), there was also a substantial amount of studies that did not consistently show such linkages. Two studies even found the opposite of what one would expect: adolescents reported more externalizing problems at times or before they had perceived more parental control (Coley et al. 2009; Rekker et al. 2017). Furthermore, the within-family studies on parental control and adolescent disclosure showed significant concurrent associations in the expected direction but found no evidence of time-lagged effects (Keijsers et al. 2016; Villalobos Solís et al. 2015). Thus, even though the idea that parental monitoring is linked to better adolescent adaptation is established with between-family studies, few empirical studies confirm that fluctuations in parental control are linked to fluctuations in adolescent adaptation within the same families. Hence, evidence for the withinfamily dynamic nature of parenting processes is still inconsistent, especially because the majority of studies did not find time-lagged effects. Whether these inconsistent results are due to heterogeneity is a question that still remains unanswered. The studies of Rekker et al. (2017) and Keijsers et al. (2016) provide first insights that the dynamic processes within families that link fluctuations in parental control to decreases or increases in adolescent adaptation may be heterogeneous and differ between families.

Furthermore, concerning other parenting dimensions, most of the studies found significant concurrent associations that were in the expected direction (e.g., increases in parental support were related to decreases in externalizing behavior and internalizing behavior) and in line with previous between-family studies (e.g., McLeod et al. 2007; Pinquart 2017b). In addition, also non-significant associations were found and one unexpected result: a macro-longitudinal study using a lower SES sample found that adolescents reported more delinquency at times their nonresidential father was more involved (Coley and Medeiros 2007). Moreover, the few studies on time-lagged associations show little evidence of time-lagged effects. Thus, the current review highlights that the evidence for the studied within-family parenting processes is quite limited, because of the inconsistent results and the lack of tested time-lagged associations. Therefore, more research is vital before firmer conclusions can be drawn with the regard to how over-time fluctuations in parenting may affect adolescents' adaptation.

In addition, the systematic review revealed some theoretical caveats in the empirical body of within-family parenting studies. Two links were of particular theoretical interest. First, psychological control or autonomy support are the key dimensions of parenting that have yet to be examined at the within-family level (for an exception, see Dietvorst et al. 2018). The self-determination theory (Ryan and Deci 2000) provides a solid theoretical foundation to expect that detrimental effects of the lack of autonomy support on adolescent adaptation would replicate at the within-family level. The theory proposes that autonomy supportive parenting satisfies the adolescent's need for autonomy and therefore enhances adolescent adaptation. Thus, in periods when parents are more autonomy supportive, their adolescents are expected to be better adapted. However, this hypothesis remains to be tested. Second, little is known about how parenting affects interpersonal peer functioning of adolescents. In light of the social learning theory (Bandura 1977), parents' behavior can serve as a model for the child. Hence, it can be expected that parent's behavior toward their children influences the 
adolescents' interpersonal behavior within other relationships, such as the peer relationship. Thus far, two daily diary studies have assessed the concurrent association between parent-child interactions and peer problems in general, but these found no supporting evidence that within-family fluctuations in parental support and parent-child conflict were related to fluctuations in adolescents' peer problems (Bai et al. 2017; Lehman and Repetti 2007). To the best of our knowledge, no studies have incorporated more elaborate indicators of interpersonal peer functioning, such as friendship support or hostility towards peers. Thus, even though parenting theories provide the conceptual frameworks for testing how changes in parenting may lead to improvements in adolescent adaptation, many theoretical ideas await testing at the within-family level where these dynamic parenting processes take place.

\section{Reciprocity Between Parents and Adolescents}

Although many of the developmental theories on parenting argue that parenting processes include bi-directional effects between parents and their children (e.g., coercion theory, monitoring literature), only eight out of 46 included studies examined reciprocal time-lagged effects, which allows for a test of such reciprocal patterns. Notably, these eight studies focused primarily on adolescent externalizing behavior. The results appeared to provide little support for some of the well-known theories that operate within families. For example, the results of the study of Besemer et al. (2016), do not support a reinforcing cycle between poor parent-child communication and externalizing behavior, which is proposed by the coercion theory (Patterson and Stouthamer-loeber 1984). In contrast, one study even found a reinforcing cycle between higher levels of father involvement and adolescent delinquency (Coley and Medeiros 2007). Moreover, evidence for Bell's theory (1968), which assumes that parents adapt their behavior when children do not show behavior within parental standards, is limited. Aside from one study, which suggested that an increase in adolescents' sexual risk behavior was related to an increase in paternal knowledge 1 year later (Coley et al. 2009), most studies did not find that externalizing behavior predicted changes in parenting related to behavioral control at the within-family level (e.g., Besemer et al. 2016; Cox et al. 2018). Thus, only a few studies have examined reciprocal time-lagged associations but did not provide strong evidence for the hypothesized reinforcing cycles of mutual influence in well-known theories, leaving the direction of the effects an open question for further research.

\section{Timescale of Parenting Processes}

Parenting processes are complex dynamic systems in which the interactions on the micro-longitudinal scale are considered to be the driving mechanisms of longer-term developmental changes (dynamics systems approach; Granic and Patterson 2006). Yet, from the current systematic review it became evident that longitudinal within-family studies typically assessed associations of parenting with adolescent adaptation on a macro-longitudinal timescale, with intervals of 6 months or longer $(k=30)$. Some of the included studies assessed processes at a daily timescale $(k=10)$, but smaller micro timescales or meso timescales that fall between daily and annual processes (e.g., weeks or months) were rare. Specifically, with respect to adolescent externalizing and internalizing behaviors, all studies were performed on a macro timescale, except for one daily diary study on internalizing behavior. Hence, whether findings can be generalized from one timescale to another is still an open question. For instance, according to the reactance theory (Brehm 1966), exerting behavioral control may result in an immediate reduction of the adolescents' problem behaviors while recurring controlling behavior may intensify problem behavior over time. Therefore, studying parenting at one timescale may lead to erroneous conclusions regarding processes at another timescale, which is referred to as the galloping horse fallacy ${ }^{1}$ (Keijsers and Van Roekel 2018).

To avoid the galloping horse fallacy and to increase the understanding of within-family parenting processes, empirical studies could consider and link different timescales (an overview of the timescales of included studies is provided in Fig. 3). For example, by implementing the Experience Sampling Method that includes multiple measurements a day (Csikszentmihalyi et al. 1977; Van Roekel et al. 2019), realtime parent-adolescent interactions can be studied. Moreover, different timescales can be linked, for example, by studying how micro-longitudinal parenting processes, such as real-time parent-adolescent interactions, develop across age and how these micro-longitudinal parenting processes are related to later developmental change. Thus, assessing parenting processes at the micro- and meso-longitudinal timescale, as well as studying how micro-dynamics change over time and accumulate into longer term developmental growth

\footnotetext{
1 The galloping horse fallacy is a metaphor referring to the work of Muybridge in his famous series of pictures 'horse in motion'. Only when he observed a galloping horse at microseconds apart, it was revealed that a galloping horse and a walking horse have a different mechanism of movement. Thus, one cannot observe a walking horse at a slower timescale to draw conclusions about how the mechanisms of galloping function at a faster timescale. Likewise, one cannot observe parenting at a one-year interval and assume that the day-today mechanisms follow the same principles.
} 
(e.g., with continuous time modelling to study within-family effects as a continuous function of time; Driver et al. 2017), would be pressing questions for future developmental research.

\section{Heterogeneity in Parenting Processes}

Theories, such as the differential susceptibility theory (Belsky and Pluess 2009), provide clear ideas about why and how parenting practices may affect adolescents differently. Nonetheless, only a limited number of studies reported the variation or heterogeneity around the average within-family association, and less than half of the studies included moderators as potential explanations. One of the potential reasons why some studies did not assess heterogeneity was their choice to model fixed effects rather than random effects in multilevel regression analyses. Consequently, variance around the slope cannot be estimated using fixed effects, which leaves an interesting aspect of heterogeneity underexplored.

One of the studies carefully highlighted the importance of assessing heterogeneity by presenting a distribution of individual effects, showing that more than half of the families had an effect size that deviated from the average withinfamily effect not only in strength but also in the direction (Farrington et al. 2002). Hence, the average within-family effect can be misleading when a parenting process is not homogenous and therefore it is recommended that average effects are generalized with caution. Thus, to avoid the "one size fits all fallacy" (considering a process to be homogenous while it is not; Keijsers and Van Roekel 2018) it is vital for future studies to explore and explain variation in withinfamily parenting processes.

\section{Strengths and Limitations}

Parenting adolescents is a complex and dynamic process, in which fluctuations in parenting may lead to fluctuations in their adolescent's adaptation, from a decline in parental support being linked to increases in internalizing problems (e.g., Johnson 1991), to increases in parental monitoring leading to decreases in externalizing problems (Patterson et al. 1984). In contrast to the well-established insights into stable differences between families in parenting and adolescent adaptation (Hoeve et al. 2009; Pinquart 2017b), this review summarizes what is currently known about the associations between fluctuations in parenting on adolescent adaptation. In other words, are adolescents better adapted in or following periods when their own parents are more controlling and supportive? By being inclusive in covering parenting and adolescent adaptation constructs, the systematic review offers a comprehensive overview of peer-reviewed studies on within-family associations between parenting and adolescent adaptation. This review showed an exponential growth in publications within the last years, as more than half of the included studies were published between 2015 and 2018. These within-family studies examine parenting processes at a level that fits better with contemporary parenting theories and demonstrate how different parenting processes sometimes may occur within different families. That is, even though a handful of studies highlighted that adolescents are better adapted in periods when their own parents are more supportive or controlling, other empirical estimates suggested that some adolescents are less well adapted in such periods.

Notwithstanding the strengths, there were also limitations. First, the review did not contain meta-analytic estimates of the included associations, because standardization methods of within-family (or within-person) effect sizes are still developing (Wang et al. 2019). Hence, it was not yet possible to compare within-family effect sizes across studies. Additionally, many associations were studied by a limited number of unique studies and samples, and mostly either on a daily or (semi- or bi-)annual timescale. Therefore, future methodological advances regarding standardization methods of multilevel effect sizes, uniformity among researchers in the use of such standardization practices, and additional studies on similar within-family parenting processes and with different timescales, appear vital for future meta-analytic assessment. Second, many studied samples were from a small number of WEIRD (Western, educated, industrial, rich, and democratic) backgrounds (Henrich et al. 2010). That is, many samples were from the United States or the Netherlands with middle-to-high socioeconomic status. To fully understand how parenting processes work within families across a wide variety of families, it is vital for future research to also study families from non-WEIRD backgrounds and to take into account differences between families in terms of ethnicity and socioeconomic status, but also for example sexual orientation (as no information was provided in the included studies). Third, the systematic search focused on peer-reviewed studies. Research that has not been peer-reviewed, such as book chapters or dissertations, may present additional insights that are not obtained through the included peer-reviewed studies. Nonetheless, it can be expected that peer-reviewed research often has higher quality standards than non-peer reviewed research and is often the knowledge on which researchers further build upon.

\section{Directions for Future Research}

To support the promising trend and forthcoming studies, three aspects seem important to consider when matching theoretical questions about parenting processes to the design of within-family studies. The first aspect is the timescale of 
observation (i.e., over-time fluctuation and measurementtimescale fit). The studies utilized various timescales, from seconds to years, although most studies focused on macrolongitudinal parenting processes. Carefully designing studies with micro and macro timescales would open up possibilities to assess how real-time and every-day processes between parents and children result in divergent patterns of developmental change in adaptation and ultimately stable differences between individuals (Back et al. 2011). However, which timescale can and needs to be included in the research design is a conceptual and methodological question, the answer to which may vary according to different parenting practices. For example, the extent to which a parent exerts behavioral control may not vary from momentto-moment but could fluctuate over a longer time, such as from month-to-month. Currently, many parenting theories do not specify the timescale(s) at which processes unfold, let alone how the timescales mutually affect each other through bottom-up and top-down causality (but see Granic and Patterson 2006). Therefore, the first challenge is to extend parenting theories to derive explicit notions regarding the critical time window in which dynamic parenting processes can be observed. Moreover, the amount of fluctuation within families and the variance that can be observed within families can depend on the fit of the measurement with the timescale. For example, when examining moment-to-moment fluctuations, items tapping into concrete behaviors that can appear in momentary states (e.g., my parent listened carefully to me) might be most appropriate, whereas measures tapping into aggregates of behavior (e.g., my parent was supportive the last 3 months) might be most appropriate at larger timescales. Thus, in addition to extending theoretical ideas, the first methodological challenge is to think carefully about whether measures are sensitive (enough) to pick up the dynamic processes at the timescale of observation.

The second conceptual-methodological factor that warrants more attention is the reciprocity between children and their parents. Despite the fact that developmental psychologists acknowledge that parenting is not a one-directional process (Pardini 2008) and that children play an active role in determining parenting practices (Stattin and Kerr 2000), the current systematic review indicated that, to date, only a limited number of studies have examined reciprocal processes of parenting and adolescent adaptation. To obtain a more accurate understanding of parenting processes within families, it is crucial to study reciprocal effects that can establish whether it is the parent affecting the child or whether the adolescent triggers changes in parenting or both.

Third, despite the possibility of heterogeneity in how parenting affects adolescent adaptation and vice versa, it is not yet a common practice to explore and explain heterogeneity in within-family parenting processes. Through modeling random multivariate slopes, researchers can obtain insights into whether within-family effects are heterogeneous across different families or even across time within the same families (e.g., Zhang et al. 2018). Moreover, it would the interesting to explain this heterogeneity, guided by relevant theories. For instance, ecological theories (Bronfenbrenner 1986; Sameroff 2010) assume contextual factors, whereas differential susceptibility theory (Belsky and Pluess 2009) assumes personality as a factor that might explain differences between families in withinfamily parenting processes.

\section{Conclusion}

A vast amount of research indicates that families differ from each other in parenting and adolescent adaptation. From between-family research, for instance, it is known that in families with more parental control and support children are generally better adapted than in other families. However, to understand the reciprocal within-family processes that link parenting and adolescent adaptation and that are proposed by contemporary theory, longitudinal studies are recommended to assess how over-time fluctuations in parenting and adolescent adaptation are linked within the same family. By conducting a systematic search, the current systematic review found that, even though such within-family studies have grown exponentially, up until the beginning of 2018 there were only 46 published studies. The results of most of the studies indicated that in periods when parents were more supportive and controlling, and parents and adolescents had less negative interaction, adolescents also reported less externalizing and internalizing behavior and other indices of maladaptation. This could suggest that changes in parent's behavior might be linked to changes in adolescents' maladaptation. Nonetheless, several studies did not find such within-family associations and a few studies even reported findings that were in the opposite direction of what would have been expected. This might be a hallmark of generally small average effect sizes but also of the existence of unmeasured moderator factors. Moreover, there is barely any evidence whether over-time fluctuations in parenting predict time-lagged fluctuations in adolescent adaptation within families or vice versa, leaving the question of reciprocity in parenting processes largely unanswered. Additionally, although a great deal of studies examined moderators, few studies actually tested whether heterogeneity in withinfamily associations existed. Hence, it is yet to be described to which extent parenting processes can differ from familyto-family. Therefore, to understand how changes in parenting, such as increasing control or becoming more supportive, may lead to changes in adolescents' adaptation over time, more studies are needed that assess the full complexity of 
these dynamic, reciprocal, and heterogeneous processes at the within-family level.

Acknowledgements We would like to thank Prof. Dr. Maja Deković for her valuable feedback on the manuscript.

Authors' Contributions SB conceived of the study, conducted the systematic search, coded the data, and wrote the article; JD helped to write the article; NM contributed to the systematic search and helped to write the article; LK conceived of the study, contributed to the systematic search, and helped to write the article. All authors read and approved the final manuscript.

Funding This research was supported by a grant from the Netherlands Organisation for Scientific Research (NWO; 452-17-011) awarded to Dr. Loes Keijsers.

Data Sharing and Declaration Data (overview of included studies) is added as online supplementary material and can also be found on https ://osf.io/6euh2/. This table will be updated regularly with new withinfamily studies on parenting and adaptation the coming years on OSF.

\section{Compliance with Ethical Standards}

Conflict of interest The authors report no conflict of interest.

Ethical Approval and Informed Consent As this research was a quantitative synthesis of already published material, no ethical approval and informed consent were required.

Open Access This article is distributed under the terms of the Creative Commons Attribution 4.0 International License (http://creativeco mmons.org/licenses/by/4.0/), which permits unrestricted use, distribution, and reproduction in any medium, provided you give appropriate credit to the original author(s) and the source, provide a link to the Creative Commons license, and indicate if changes were made.

\section{References}

\section{*Included in the literature review}

Achenbach, T. M., \& Edelbrock, C. S. (1987). Manual for the youth self-report and profile. Beverly Hills, CA: Sage.

*Allen, N. B., Kuppens, P., \& Sheeber, L. B. (2012). Heart rate responses to parental behavior in depressed adolescents. Biological Psychology, 90, 80-87. https://doi.org/10.1016/j.biops ycho.2012.02.013.

Back, M. D., Baumert, A., Denissen, J. J. A., Hartung, F.-M., Penke, L., Schmukle, S. C., ... Wrzus, C. (2011). PERSOC: A unified framework for understanding the dynamic interplay of personality and social relationships. European Journal of Personality, 25 , 90-107. https://doi.org/10.1002/per.811.

*Bai, S., Reynolds, B. M., Robles, T. F., \& Repetti, R. L. (2017). Daily links between school problems and youth perceptions of interactions with parents: A diary study of school-to-home spillover. Social Development, 26, 813-830. https://doi.org/10.1111/ sode. 12229.

Bandura, A. (1977). Social learning theory. Englewood Cliffs, NJ: Prentice-Hall.
Baumrind, D. (1971). Current patterns of parental authority. Developmental Psychology, 4, 1-103. https://doi.org/10.1037/h0030372.

Bell, R. Q. (1968). A reinterpretation of the direction of effects in studies of socialization. Psychological Review, 75, 81-95.

Belsky, J., \& Pluess, M. (2009). Beyond diathesis stress: Differential susceptibility to environmental influences. Psychological Bulletin, 135, 885-908. https://doi.org/10.1037/a0017376.

Berry, D., \& Willoughby, M. T. (2017). On the practical interpretability of cross-lagged panel models: Rethinking a developmental workhorse. Child Development, 88, 1186-1206. https://doi. org/10.1111/cdev.12660.

*Besemer, S., Loeber, R., Hinshaw, S. P., \& Pardini, D. A. (2016). Bidirectional associations between externalizing behavior problems and maladaptive parenting within parent-son dyads across childhood. Journal of Abnormal Child Psychology, 44, 1387-1398. https://doi.org/10.1007/s10802-015-0124-6.

Branje, S. (2018). Development of parent-adolescent relationships: Conflict interactions as a mechanism of change. Child Development Perspectives, 12, 171-176. https://doi.org/10.1111/ cdep. 12278.

*Brauer, J. R. (2009). Testing social learning theory using reinforcement's residue: a multilevel analysis of self-reported theft and marijuana use in the national youth survey. Criminology, 47, 929-970. https://doi.org/10.1111/j.1745-9125.2009.00164.x.

Brehm, J. W. (1966). A theory of psychological reactance. Oxford, England: Academic Press.

Bronfenbrenner, U. (1986). Ecology of the family as a context for human development: Research perspectives. Developmental Psychology, 22, 723-742.

*Chung, G. H., Flook, L., \& Fuligni, A. J. (2009). Daily family conflict and emotional distress among adolescents from Latin American, Asian, and European backgrounds. Developmental Psychology, 45, 1406-1415. https://doi.org/10.1037/a0014163.

*Coley, R. L., \& Medeiros, B. L. (2007). Reciprocal longitudinal relations between nonresident father involvement and adolescent delinquency. Child Development, 78, 132-147. https://doi. org/10.1111/j.1467-8624.2007.00989.x.

*Coley, R. L., Votruba-drzal, E., \& Schindler, H. S. (2009). Fathers' and mothers' parenting predicting and responding to adolescent sexual risk behaviors. Child Development, 80, 808-827.

*Coley, R. L., Votruba-Drzal, E., \& Schindler, H. S. (2008). Trajectories of parenting processes and adolescent substance use: Reciprocal effects. Journal of Abnormal Child Psychology, 36(4), 613-625. https://doi.org/10.1007/s10802-007-9205-5.

*Cox, M. J., Ennett, S. T., Foshee, V., Hussong, A., Lippold, M., \& McNaughton-Reyes, H. L. (2018). Bidirectional relationships between alcohol-specific parental socialization behaviors and adolescent alcohol misuse. Substance Use and Misuse, 0, 1-12. https://doi.org/10.1080/10826084.2017.1421663.

*Crowell, S. E., Baucom, B. R., Yaptangco, M., Bride, D., Hsiao, R., McCauley, E., et al. (2014). Emotion dysregulation and dyadic conflict in depressed and typical adolescents: evaluating concordance across psychophysiological and observational measures. Biological Psychology, 98, 50-58. https://doi. org/10.1016/j.biopsycho.2014.02.009.

Csikszentmihalyi, M., Larson, R., \& Prescott, S. (1977). The ecology of adolescent activity and experience. Journal of Youth and Adolescence, 6, 281-294. https://doi.org/10.1007/BF02138940.

Darling, N., \& Steinberg, L. (1993). Parenting style as context: An integrative model. Psychological Bulletin, 113, 487-496.

*Dietvorst, E., Hiemstra, M., Hillegers, M. H. J., \& Keijsers, L. (2018). Adolescent perceptions of parental privacy invasion and adolescent secrecy: An illustration of simpson's paradox. Child Development, 89, 2081-2090. https://doi.org/10.1111/ cdev.13002. 
Driver, C. C., Oud, J. H. L., \& Voelkle, M. C. (2017). Continuous time structural equation modeling with $\mathrm{R}$ package ctsem. Journal of Statistical Software, 77, 1-35. https://doi.org/10.18637/jss.v077. i05.

*Farrington, D. P., Loeber, R., Yin, Y., \& Anderson, S. J. (2002). Are within-individual causes of delinquency the same as betweenindividual causes? Criminal Behaviour and Mental Health, 12, 53-68. https://doi.org/10.1002/cbm.486.

*Gottfredson, N. C., \& Hussong, A. M. (2011). Parental involvement protects against self-medication behaviors during the high school transition. Addictive Behaviors, 36, 1246-1252. https://doi. org/10.1016/j.addbeh.2011.07.035.

*Gottfredson, N. C., Hussong, A. M., Ennett, S. T., \& Rothenberg, W. A. (2017). The role of parental engagement in the intergenerational transmission of smoking behavior and identity. The Journal of Adolescent Health, 60, 599-605. https://doi.org/10.1016/j.jadoh ealth.2016.11.004

Granic, I., \& Patterson, G. R. (2006). Toward a comprehensive model of antisocial development: A dynamic systems approach. Psychological Review, 113, 101-131. https://doi. org/10.1037/0033-295X.113.1.101.

*Grundy, A. M., Gondoli, D. M., \& Blodgett Salafia, E. H. (2010). Hierarchical linear modeling analysis of change in maternal knowledge over the transition to adolescence. Journal of Early Adolescence, 30, 707-732. https://doi.org/10.1177/0272431609 341047

Hamaker, E. L. (2012). Why researchers should think "within-person”: A paradigmatic rationale. In M. R. Mehl \& T. S. Conner (Eds.), Handbook of research methods for studying daily life (pp. 43-61). New York: Guilford.

Hamaker, E. L., Kuiper, R. M., \& Grasman, R. P. P. P. (2015). A critique of the cross-lagged panel model. Psychological Methods, 20, 102-116. https://doi.org/10.1037/a0038889.

*Han, Y., \& Grogan-Kaylor, A. (2013). Parenting and youth psychosocial well-being in South Korea using fixed-effects models. Journal of Family Issues, 34, 689-715. https://doi.org/10.1177/01925 13X12440091.

Henrich, J., Heine, S. J., \& Norenzayan, A. (2010). The weirdest people in the world? Behavioral and Brain Sciences, 33, 61-83. https:// doi.org/10.1017/S0140525X0999152X.

Hoeve, M., Dubas, J. S., Eichelsheim, V. I., Van Der Laan, P. H., Smeenk, W., \& Gerris, J. R. M. (2009). The relationship between parenting and delinquency: A meta-analysis. Journal of Abnormal Child Psychology, 37, 749-775. https://doi.org/10.1007/s1080 2-009-9310-8.

*Janssen, H. J., Bruinsma, G. J. N., Deković, M., \& Eichelsheim, V. I. (2018). A between- and within-person analysis of parenting and time spent in criminogenic settings during adolescence: The role of self-control and delinquent attitudes. Youth and Society, 50, 229-254. https://doi.org/10.1177/0044118X16636138.

*Janssen, H. J., Dekovic, M., \& Bruinsma, G. J. N. N. (2014). Parenting and time adolescents spend in criminogenic settings: A betweenand within-person analysis. British Journal of Criminology, 54, 551-567. https://doi.org/10.1093/bjc/azu032.

*Janssen, H. J., Eichelsheim, V. I., Deković, M., \& Bruinsma, G. J. N. (2016). How is parenting related to adolescent delinquency? A between- and within-person analysis of the mediating role of self-control, delinquent attitudes, peer delinquency, and time spent in criminogenic settings. European Journal of Criminology, 13, 169-194. https://doi.org/10.1177/1477370815608881.

*Janssen, H. J., Weerman, F. M., \& Eichelsheim, V. I. (2017). Parenting as a protective factor against criminogenic settings? Interaction effects between three aspects of parenting and unstructured socializing in disordered areas. Journal of Research in Crime and Delinquency, 54, 181-207. https://doi.org/10.1177/0022427816664561.
Johnson, T. P. (1991). Mental health, social relations, and social selection: A longitudinal analysis. Journal of Health and Social Behavior, 32, 408-423.

*Keijsers, L. (2016). Parental monitoring and adolescent problem behaviors: How much do we really know? International Journal of Behavioral Development, 40, 271-281. https://doi. org/10.1177/0165025415592515.

Keijsers, L., Branje, S., Hawk, S. T., Schwartz, S. J., Frijns, T., \& Koot, H. M. (2012). Forbidden friends as forbidden fruit: Parental supervision of friendships, contact with deviant peers, and adolescent delinquency. Child Development, 83, 651-666. https://doi.org/10 $.1111 /$ j.1467-8624.2011.01701.x.

Keijsers, L., \& van Roekel, E. (2018). Longitudinal methods in adolescent psychology: Where could we go from here? And should we? In L. B. Hendry \& M. Kloep (Eds.), Reframing adolescent research (pp. 70-91). London: Routledge.

*Keijsers, L., Voelkle, M. C., Maciejewski, D., Branje, S., Koot, H., Hiemstra, M., et al. (2016). What drives developmental change in adolescent disclosure and maternal knowledge? Heterogeneity in within-family processes. Developmental Pyschology, 52, 2057-2070. https://doi.org/10.1037/dev0000220.

Kerr, M., \& Stattin, H. (2000). What parents know, how they know it, and several forms of adolescent adjustment: Further support for a reinterpretation of monitoring. Developmental Psychology, 36, 366-380.

*Kuhlman, K. R., Repetti, R. L., Reynolds, B. M., \& Robles, T. F. (2016). Change in parent-child conflict and the HPA-axis: Where should we be looking and for how long? Psychoneuroendocrinology, 68, 74-81. https://doi.org/10.1016/j.psyne uen.2016.02.029. Change.

*Laird, R. D., Pettit, G. S., Bates, J. E., \& Dodge, K. A. (2003). Parents' monitoring-relevant knowledge and adolescents' delinquent behavior: Evidence of correlated developmental changes and reciprocal influences. Child Development, 74, 752-768. https://doi.org/10.1080/10810730902873927.Testing.

*Lam, C. B., Greene, K. M., \& McHale, S. M. (2016). Housework time from middle childhood through adolescence: Links to parental work hours and youth adjustment. Developmental Psychology, 52, 2071-2084. https://doi.org/10.1037/dev0000223.

*Lam, C. B., \& McHale, S. M. (2015). Developmental patterns and parental correlates of youth leisure-time physical activity. Journal of Family Psychology, 29, 100-107. https://doi.org/10.1037/ fam0000049.

*Lau, E. Y., Faulkner, G., Qian, W., \& Leatherdale, S. T. (2016). Longitudinal associations of parental and peer influences with physical activity during adolescence: Findings from the COMPASS study. Health Promotion and Chronic Disease Prevention in Canada: Research, Policy, and Practice, 36, 235-242.

*Lehman, B. J., \& Repetti, R. L. (2007). Bad days don't end when the school bell rings: The lingering effects of negative school events on children's mood, self-esteem, and perceptions of parent-child interaction. Social Development, 16, 596-618. https ://doi.org/10.1111/j.1467-9507.2007.00398.x.

*Lippold, M. A., Davis, K. D., McHale, S. M., \& Almeida, D. M. (2016a). Daily parental knowledge of youth activities is linked to youth physical symptoms and HPA functioning. Journal of Family Psychology, 30, 245-253. https://doi.org/10.1037/fam00 00167.

*Lippold, M. A., McHale, S. M., Davis, K. D., Almeida, D. M., \& King, R. B. (2016b). Experiences with parents and youth physical health symptoms and cortisol: A daily diary investigation. Journal of Research on Adolescence, 26, 226-240. https://doi. org/10.1111/jora.12186.

Maciejewski, D. F., Keijsers, L., Branje, S., \& Meeus, W. H. J. (2019). Most fare well-But some do not: Distinct profiles of mood variability development and their association with adjustment during 
adolescence. Development Psychology, 55, 434-448. https://doi. org/10.1037/dev0000650.

McLeod, B. D., Wood, J. J., \& Weisz, J. R. (2007). Examining the association between parenting and childhood anxiety: A metaanalysis. Clinical Psychology Review, 27, 155-172. https://doi. org/10.1016/j.cpr.2006.09.002.

Meeus, W. (2016). Adolescent psychosocial development: A review of longitudinal models and research. Developmental Psychology, 52, 1969-1993.

*Meldrum, R. C., Young, J. T. N., \& Weerman, F. M. (2012). Changes in self-control during adolescence: Investigating the influence of the adolescent peer network. Journal of Criminal Justice, 40, 452-462. https://doi.org/10.1016/j.jcrimjus.2012.07.002.

Molenaar, P. C. M. (2004). A manifesto on psychology as idiographic science: Bringing the person back into scientific psychology, this time forever. Measurement Interdisciplinary Research and Perspectives, 2, 201-218. https://doi.org/10.1207/s15366359m ea0204.

*Padilla, J., McHale, S. M., Updegraff, K. A., \& Umaña-Taylor, A. J. (2016). Mexican-origin parents' differential treatment and siblings' adjustment from adolescence to young adulthood. Journal of Family Psychology, 30, 955-965. https://doi.org/10.1037/fam00 00229.

*Papp, L. M., Pendry, P., \& Adam, E. K. (2009). Mother-adolescent physiological synchrony in naturalistic settings: Within-family cortisol associations and moderators. Journal of Family Psychology, 23, 882-894. https://doi.org/10.1037/a0017147.

Pardini, D. A. (2008). Novel insights into longstanding theories of bidirectional parent-child influences: Introduction to the special section. Journal of Abnormal Child Psychology, 36, 627-631. https://doi.org/10.1007/s10802-008-9231-y.

Patterson, G. R. (1982). Coercive family process. Eugene, OR: Castalia Publishing Company.

Patterson, G. R., Dishion, T. J., \& Bank, L. (1984). Family interaction: A process model of deviancy training. Aggressive Behavior, 10, 253-267.

Patterson, G. R., \& Stouthamer-loeber, M. (1984). The correlation of family management practices and delinquency. Child Development, 55, 1299-1307.

Pinquart, M. (2017a). Associations of parenting dimensions and styles with externalizing problems of children and adolescents: An updated meta-analysis. Developmental Psychology, 53, 873-932. https://doi.org/10.1037/dev0000295.

Pinquart, M. (2017b). Associations of parenting dimensions and styles with internalizing symptoms in children and adolescents: A metaanalysis. Marriage and Family Review, 53, 613-640. https://doi. org/10.1080/01494929.2016.1247761.

*Rekker, R., Keijsers, L., Branje, S., Koot, H., \& Meeus, W. (2017). The interplay of parental monitoring and socioeconomic status in predicting minor delinquency between and within adolescents. Journal of Adolescence, 59, 155-165. https://doi.org/10.1016/j. adolescence.2017.06.001.

*Rekker, R., Pardini, D., Keijsers, L., Branje, S., Loeber, R., \& Meeus, W. (2015). Moving in and out of poverty: The withinindividual association between socioeconomic status and juvenile delinquency. PLoS ONE, 10, e0136461-e0136461. https:// doi.org/10.1371/journal.pone.0136461.

*Reyes, H. L. M., Foshee, V. A., Tharp, A. T., Ennett, S. T., \& Bauer, D. J. (2015). Substance use and physical dating violence. American Journal of Preventive Medicine, 49, 467-475. https://doi. org/10.1016/j.amepre.2015.05.018.

*Reynolds, B. M., Robles, T. F., \& Repetti, R. L. (2016). Measurement reactivity and fatigue effects in daily diary research with families. Developmental Psychology, 52, 442-456. https://doi.org/10.1037/ dev0000081.
*Richmond, M. K., Stocker, C. M., \& Rienks, S. L. (2005). Longitudinal associations between sibling relationship quality, parental differential treatment, and children's adjustment. Journal of Family Psychology, 19, 550-559. https://doi. org/10.1037/0893-3200.19.4.550.

*Robles, T. F., Carroll, J. E., Bai, S., Reynolds, B. M., Esquivel, S., \& Repetti, R. L. (2016). Emotions and family interactions in childhood: Associations with leukocyte telomere length. Psychoneuroendocrinology, 63, 343-350. https://doi.org/10.1016/j.psyne uen.2015.10.018.

Rote, W. M., \& Smetana, J. G. (2018). Within-family dyadic patterns of parental monitoring and adolescent information management. Development Psychology, 54, 2302-2315. https://doi.org/10.1037/ dev0000615.

Ryan, R. M., \& Deci, E. L. (2000). Self-determination theory and the facilitation of intrinsic motivation, social development, and wellbeing. American Psychologist, 55, 68-78. https://doi.org/10.1002/ jsfa.2740050407.

Sameroff, A. (2010). A unified theory of development: A dialectic integration of nature and nurture. Child Development, 81, 6-22. https://doi.org/10.1111/j.1467-8624.2009.01378.x.

*Shanahan, L., McHale, S. M., Crouter, A. C., \& Osgood, D. W. (2008). Linkages between parents' differential treatment, youth depressive symptoms, and sibling relationships. Journal of Marriage and Family, 70, 480-494. https://doi.org/10.111 1/j.1741-3737.2008.00495.x.

Slagt, M., Dubas, J. S., Denissen, J. J. A., Deković, M., \& van Aken, M. A. G. (2015). Personality traits as potential susceptibility markers: Differential susceptibility to support among parents. Journal of Personality, 83, 155-166. https://doi.org/10.1111/jopy.12091.

Smith, L. B., \& Thelen, E. (2003). Development as a dynamic system. Trends in Cognitive Sciences, 7, 343-348. https://doi.org/10.1016/ S1364-6613(03)00156-6.

Soenens, B., Vansteenkiste, M., Lens, W., Luyckx, K., Goossens, L., Beyers, W., et al. (2007). Conceptualizing parental autonomy support: Adolescent perceptions of promotion of independence versus promotion of volitional functioning. Developmental Psychology, 43, 633-646. https://doi.org/10.1037/0012-1649.43.3.633.

Soenens, B., Vansteenkiste, M., \& Van Petegem, S. (2015). Let us not throw out the baby with the bathwater: Applying the principle of universalism without uniformity to autonomy-supportive and controlling parenting. Child Development Perspectives, 9, 44-49. https://doi.org/10.1111/cdep.12103.

Stattin, H., \& Kerr, M. (2000). Parental monitoring: A reinterpretation. Child Development, 71, 1072-1085. https://doi.org/10.1111/14678624.00210.

*Svensson, R., Pauwels, L. J. R., Weerman, F. M., \& Bruinsma, G. J. N. (2017). Explaining individual changes in moral values and moral emotions among adolescent boys and girls: A fixed-effects analysis. European Journal of Criminology, 14, 290-308. https ://doi.org/10.1177/1477370816649626.

*Timmons, A. C., \& Margolin, G. (2015). Family conflict, mood, and adolescents' daily school problems: Moderating roles of internalizing and externalizing symptoms. Child Development, 86, 241-258. https://doi.org/10.1002/ar.20849.3D.

Van Roekel, E., Keijsers, L., \& Chung, J. M. (2019). A review of current ambulatory assessment studies in adolescent samples and practical recommendations. Journal of Research on Adolescence, $1-49$.

*Vandewalle, J., Mabbe, E., Debeuf, T., Braet, C., \& Moens, E. (2017). The daily relation between parental rejection and emotional eating in youngsters: A diary study. Frontiers in Psychology, 8, 1-8. https://doi.org/10.3389/fpsyg.2017.00691.

*Vaughan, C. A., Foshee, V. A., \& Ennett, S. T. (2010). Protective effects of maternal and peer support on depressive symptoms 
during adolescence. Journal of Abnormal Child Psychology, 38, 261-272. https://doi.org/10.1007/s10802-009-9362-9.

*Villalobos Solís, M., Smetana, J. G., \& Comer, J. (2015). Associations among solicitation, relationship quality, and adolescents' disclosure and secrecy with mothers and best friends. Journal of Adolescence, 43, 193-205. https://doi.org/10.1016/j.adolescenc e.2015.05.016.

Wang, L., Zhang, Q., Maxwell, S. E., Bergeman, C. S., Wang, L., Zhang, Q., ... On, C. S. B. (2019). On standardizing within-person effects: Potential problems of global standardization. Multivariate Behavioral Research, 54, 1-22. https://doi.org/10.1080/00273 171.2018.1532280.
*Zhang, S., Baams, L., van de Bongardt, D., \& Dubas, J. S. (2018). Intra- and inter-individual differences in adolescent depressive mood: The role of relationships with parents and friends. Journal of Abnormal Child Psychology, 46, 811-824. https://doi. org/10.1007/s10802-017-0321-6.

Publisher's Note Springer Nature remains neutral with regard to jurisdictional claims in published maps and institutional affiliations. 